\title{
GLUTAMIC ACID DECARBOXYLASE-IMMUNOREACTIVE NEURONS AND HORSERADISH PEROXIDASE-LABELED PROJECTION NEURONS IN THE VENTRAL POSTERIOR NUCLEUS OF THE CAT AND GALAGO SENEGALENSIS ${ }^{1}$
}

\author{
G. R. PENNY,2 D. FITZPATRICK, D. E. SCHMECHEL, AND I. T. DIAMOND \\ Neurobiology Program and Department of Psychology, and Division of Neurology, Department of Medicine, Duke University, \\ Durham, North Carolina 27706
}

Received September 15, 1982; Revised January 17, 1983; Accepted January 18, 1983

\begin{abstract}
Immunocytochemical methods were used to identify neurons in the ventral posterior nucleus of the cat and Galago senegalensis that contain glutamic acid decarboxylase (GAD), the synthetic enzyme for the inhibitory neurotransmitter, GABA. In both species GAD-immunoreactive neurons make up about $30 \%$ of the total neurons in the ventral posterior nucleus and form a distinct class of small cells. After cortical injections of horseradish peroxidase (HRP), GAD-immunoreactive cells are not labeled with HRP and may, therefore, be GABAergic local circuit neurons. Comparison of the dendritic morphology of GAD-immunoreactive neurons with that of HRP-filled projection neurons reveals that the morphology of the GAD-containing neurons is distinct and, in particular, that the GAD-immunoreactive neurons display fewer primary dendrites. The relay neurons, in turn, can be divided into classes based on dendritic morphology and cell body size.
\end{abstract}

The idea that thalamic neurons could be divided into classes based on morphological criteria has a long history. According to Ramón y Cajal $(1909,1966)$, the most fundamental distinction was between the neurons with long axons that project to the cerebral cortex and neurons with short axons that were thought to be local circuit neurons. Cajal found the neurons with short axons or "cellules á cylindre-axe court" to be distributed widely in the nervous system and to be especially numerous in the thalamus and neocortex of higher mammals. The neurons with long axons (or projection neurons) could be further subdivided into classes based on their appearance in Golgi material. Tömböl recently (1967) identified at least two classes in the case of the somatosensory ventral posterior nucleus of the cat.

\footnotetext{
${ }^{1}$ This work was supported by National Institute of Mental Health Research Grant 04948 and National Science Foundation Research Grant BNS-7915780 (to I. T. D.) and National Institute of Mental Health Predoctoral Fellowship 08312 (to G. R. P.). We would like to thank Shari Alexander, Kathy Beck, Lynn Conley, and Susan Havrilesky for their help in preparing the illustrations and manuscript, and Enrico Mugnaini for helpful suggestions. We would also like to thank Roberto Spreafico and Aldo Rustioni for generously providing us with their unpublished results.

${ }^{2}$ To whom correspondence should be addressed.
}

It is natural to try to relate the morphological classes of neurons to differences in function and connections. For example, Eccles suggested that neurons with short axons might subserve local circuit inhibition. He and his collaborators were able to demonstrate the inhibitory role of Renshaw cells and type Ia interneurons of the spinal gray; they went on to propose that inhibition throughout the brain is mediated by neurons with short axons (Brooks and Eccles, 1947; Eccles et al., 1954, 1956). In later studies Anderson and Eccles et al. $(1962,1964 \mathrm{a}$, b) demonstrated presynaptic and postsynaptic inhibition within the ventrobasal complex and postulated that this inhibition was mediated by thalamic neurons with short axons (see Rakic, 1976, for a more extensive historical review of local circuit neurons).

So far our own studies of the ventral group of thalamic nuclei have been restricted to the projection neurons. We have found evidence that small projection neurons in the ventral group of thalamic nuclei, including the ventral posterior nucleus, arborize in more superficial layers of the somatic cortex than do larger neurons (Penny et al. 1982a).

The observation that some very small neurons in the ventral posterior nucleus had connections with the cerebral cortex led us to reconsider the traditional distinction between thalamic local circuit neurons (which were 
thought to be very small) and thalamic neurons with projections to the cerebral cortex. This distinction has been called into question on other grounds, for example, by Saporta and Kruger (1979), who found few neurons left unlabeled in the ventral posterior nucleus of the cat after horseradish peroxidase (HRP) injections into the somatosensory cortex.

In the present study we use immunocytochemical methods for the localization of the synthetic enzyme glutamic acid decarboxylase (GAD) to identify neurons in the ventral posterior nucleus of the cat and the prosimian Galago that, presumably, use the inhibitory neurotransmitter $\gamma$-aminobutyric acid (GABA) (Kuriyama et al., 1966; Roberts and Kuriyama, 1968; Fonnum and Walberg, 1973; McLaughlin et al., 1974; Fahn, 1976). We use the HRP transport method to identify neurons in the ventral posterior nucleus that project to the somatosensory cortex. The questions addressed include: (1) What proportion of the neurons in the ventral posterior nucleus of these species are GAD immunoreactive? (2) Can these neurons be labeled by HRP transported from cortex? (3) How does the morphology of GAD-positive neurons compare with that of other classes of neurons in the ventral posterior nucleus? Some of these results have been presented previously in abstract form (Fitzpatrick et al., 1982; Penny et al., 1982b).

\section{Materials and Methods}

Tissue from the brains of 10 cats and four Galago senegalensis was used in this study. Prior to sacrifice the cats were deeply anesthetized and then perfused through the heart with approximately 1 liter of $38^{\circ} \mathrm{C}$ of $0.5 \%$ zinc salicylate dissolved in $10 \%$ formalin in $\mathrm{H}_{2} \mathrm{O}$ followed by 2 liters of $10 \%$ formalin in $\mathrm{H}_{2} \mathrm{O}$ at $4^{\circ} \mathrm{C}$, and, finally, 1 liter at $4^{\circ} \mathrm{C}$ of $10 \%$ sucrose in $0.1 \mathrm{M}$ phosphate buffer, $\mathrm{pH} 7.6$, containing $2 \%$ dimethyl sulfoxide. These volumes were halved in the case of perfusions of Galago. This perfusion fixation is a modification of a procedure described by Mugnaini and Dahl (1983).

Sections through the thalamus were cut coronally at $30 \mu \mathrm{m}$ on a freezing microtome or at 15 to $20 \mu \mathrm{m}$ on an Oxford (Laneer) Vibratome and saved in $0.01 \mathrm{M}, \mathrm{pH} 7.6$, phosphate-buffered saline (PBS). The sections were processed for GAD immunocytochemistry using the unlabeled antibody-enzyme (PAP) method (Sternberger, 1979 ) or the avidin-biotinylated horseradish peroxidase complex (ABC) method (Hsu et al., 1981).

We used the antiplasma to GAD developed by Oertel, Schmechel, and Tappaz (Oertel et al., 1981, 1983). Sections were incubated in primary antiplasma diluted $1: 2000$ in $0.02 \mathrm{M}$ phosphate buffer with $0.9 \%$ saline (PBS). Control sections were incubated in pre-immune sheep plasma diluted 1:1000 in PBS. The ABC or PAP complexes were localized by reaction with $100 \mathrm{mg} / 100$ $\mathrm{ml}$ of $3,3^{\prime}$-diaminobenzidine tetrahydrochloride (DAB) in PBS.

In two cats and two Galago, injections of HRP were made in the somatosensory (SI) cortex in order to identify cells in the ventral posterior nucleus that project to cortex. Multiple injections of $0.1 \mu \mathrm{l}$ of $20 \% \mathrm{HRP}$ (Toyobo Co., Japan) dissolved in $0.1 \mathrm{M}, \mathrm{pH} 7.6$ trizma buffer with
$2 \%$ lysophosphatidyl choline (Sigma Chemical Co.) were made in a single cerebral hemisphere using a Hamilton syringe attached to a glass micropipette. A third cat received a local injection of HRP in the ventral posterior nucleus via iontophoresis (25- $\mu \mathrm{m}$ glass micropipette tip, $2 \mu \mathrm{A}, 20 \mathrm{~min}$, Midgard constant current source). A double label method was used to identify in a single section both neurons containing transported HRP and neurons displaying GAD immunoreactivity. The $15-$ to $20-\mu \mathrm{m} \mathrm{Vi}-$ bratome sections were first processed for transported $\mathrm{HRP}$ according to the $\mathrm{CoCl}_{2}-\mathrm{DAB}$ protocol (Adams, 1977), which yields a granular black reaction product. The sections were then stored overnight in $5 \%$ formalin in PBS in order to destroy the enzymatic activity of the transported HRP. Subsequently, the sections were processed for GAD immunoreactivity by the ABC method. $\mathrm{DAB}$ alone was used as the immunological chromagen, producing a uniform brown reaction product. This method produced brown-labeled GAD-immunoreactive neurons and granular black-labeled neurons containing transported HRP. The black granular HRP label was clearly distinguishable from the brown label for cell bodies and terminals of GAD-immunoreactive neurons. Some double-labeled sections were counterstained with cresyl violet. In these sections the neurons displayed dark violet nucleoli and light violet cytoplasms as well as the brown or black label for GAD or transported HRP. One difficulty with the preceding double label method is that the $\mathrm{CoCl}_{2}-\mathrm{DAB}$ reaction in some instances produced brown background labeling in cells labeled by granular black reaction product. Sets of sections in which this occurred were rejected prior to further processing. Partly because of this previous limitation, we also used a second double labeling method which employed DAB as the chromagen for indicaling the presence of transported HRP and $100 \mathrm{mg} / 100 \mathrm{ml}$ of 4-chloro-1-naphthol with $0.001 \% \mathrm{H}_{2} \mathrm{O}_{2}$ in PBS as the chromagen for indicating the presence of GAD immunoreactivity (Nakane, 1968). This method produced brown neurons containing HRP and granular blue-labeled GAD-immunoreactive neurons. Since the 4-chloro-1-naphthol reaction product is soluble in alcohols, sections processed according to this second method were allowed to dry on gelatin-coated slides and were then coverslipped using glycerin. It was not possible to counterstain these sections.

Measurements of cell body areas were made from cresyl violet-counterstained sections processed for GAD immunoreactivity, counterstained sections processed for both GAD immunoreactivity and HRP transport, and sections stained only with cresyl violet. Cell bodies were drawn at $\times 1667$ using a $\times 100$ oil immersion objective and a camera lucida. From these drawings the cell body areas were calculated using an Apple graphics tablet and computer. Rectangular sample areas were defined in the medial division of the ventral posterolateral nucleus, and every neuron displaying a nucleolus was drawn through the plane of the nucleolus. The sample areas were 0.16 $\mathrm{mm}^{2}$ in area in Galago and $0.26 \mathrm{~mm}^{2}$ in the cat. Statistical methods for comparison of the samples were taken from Siegel (1956).

The percentage of GAD-immunoreactive neurons in 
the ventral posterior nucleus was estimated by counting the relative numbers of GAD-immunoreactive neurons and unlabeled Nissl-stained neurons in samples taken from counterstained sections. The estimated percentage was calculated according to the formula: $\% \mathrm{GAD}=100$ $\times(\mathrm{GAD} /(\mathrm{GAD}+$ unlabeled Nissl $))$. In counts taken from the double label material, the number of HRPlabeled neurons was substituted in the formula in place of the number of unlabeled Nissl neurons.

For purposes of comparison, cell body areas of GADimmunoreactive neurons were also measured in sections that were not counterstained with cresyl violet. Cells were drawn if they displayed a clear nucleus. Matching Nissl counts for this material were taken from adjacent sections which had been counterstained but not processed for GAD immunoreactivity. Some of these measurements were taken from 0.16 or $0.26 \mathrm{~mm}^{2}$ sample areas; others were from drawings of 100 each of GAD and unlabeled Nissl-stained cells. Because of the difficulty of choosing precisely equivalent areas in adjacent sections, estimates of the relative percentages of GAD and nonGAD neurons were not made from the uncounterstained material.

In two additional cats, injections of HRP were made in the somatosensory cortex by the methods described previously, and $100-\mu \mathrm{m}$ frozen sections through the ventral posterior nucleus were reacted by the Streit and Reubi (1977) method for transported HRP. This procedure produced Golgi-like filling of projection neurons in the ventral posterior nucleus. Examples of these neurons were drawn at $\times 1667$, using a $\times 100$ oil immersion objective and a camera lucida.

\section{Results}

Size and distribution of $G A D$-immunoreactive neurons and terminals. GAD-immunoreactive neurons are char- acterized in the DAB-reacted material by dark brown cell bodies and primary dendrites. The first and most obvious result is that these cells are distributed throughout the dorsal thalamus in both the cat and Galago. The only apparent exception to this rule is made by the centre median and parafascicular nuclei; these nuclei display fine GAD-immunoreactive terminals but no cell bodies.

GAD-immunoreactive terminals are also distributed throughout the dorsal thalamus, but their density varies greatly, such that the thalamic nuclei can be readily distinguished based on the pattern of staining of GADimmunoreactive terminals. The most densely distributed GAD-immunoreactive terminals are found in the lateral geniculate nucleus, the ventral posterior nucleus, the ventral division of the medial geniculate complex, the central lateral nucleus, and the pulvinar nucleus. Some of these differences in terminal distribution can be seen in Figure 1, which includes two photomicrographs of coronal thalamic sections from the cat $(A)$ and Galago $(B)$. The ventral posterolateral nucleus is indicated in both photomicrographs; in the cat it is more densely filled by GAD-immunoreactive terminals than in the Galago. The large neurons of the ventral thalamic reticular nucleus (Ret) are also strongly positive for GAD, as has been reported previously (Houser et al., 1980).

Figure $2 A$ is a view of the Galago ventral posterior nucleus, displaying GAD-immunoreactive terminals and cells and corresponding to the area indicated by the four markers in Figure $2 B$. In order to show that the results are not the result of nonspecific labeling, we show for contrast in Figure $2 B$ a matching control section, incubated in pre-immune sheep plasma. It displays no labeling of terminals and cells.

Figure $3 A$ shows a photomicrograph of the ventral posterior nucleus of the cat processed for GAD immunoreactivity and then counterstained with cresyl violet.
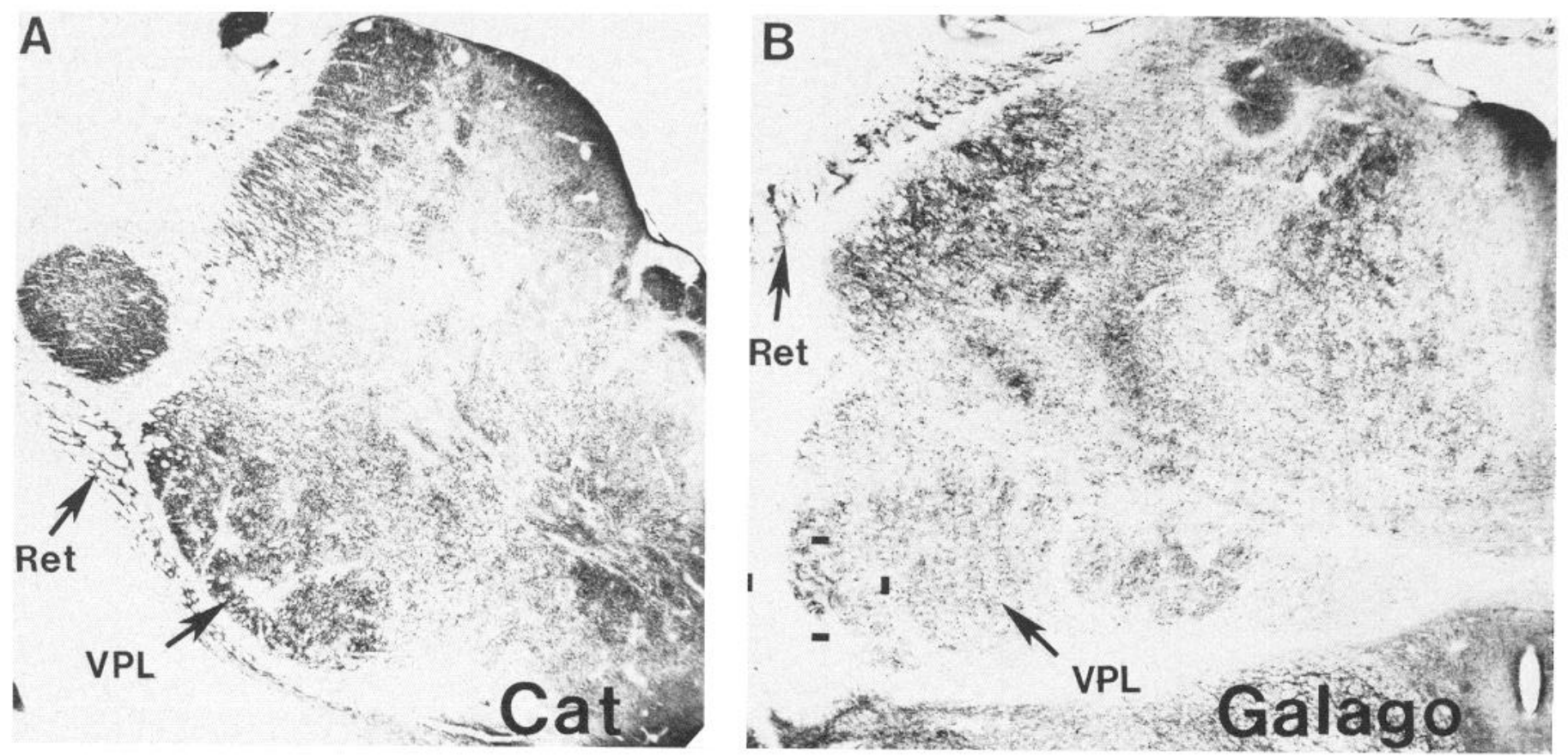

Figure 1. Photomicrographs of coronal sections through the thalamus of the cat $(A)$ and Galago $(B)$ showing the distribution of GAD immunoreactivity. Arrows indicate the thalamic reticular nucleus (Ret) and the ventral posterolateral nucleus ( $V P L$ ). The four markers in the ventral posterolateral nucleus of Galago indicate the boundaries of the region shown in Figure $2 A$. 


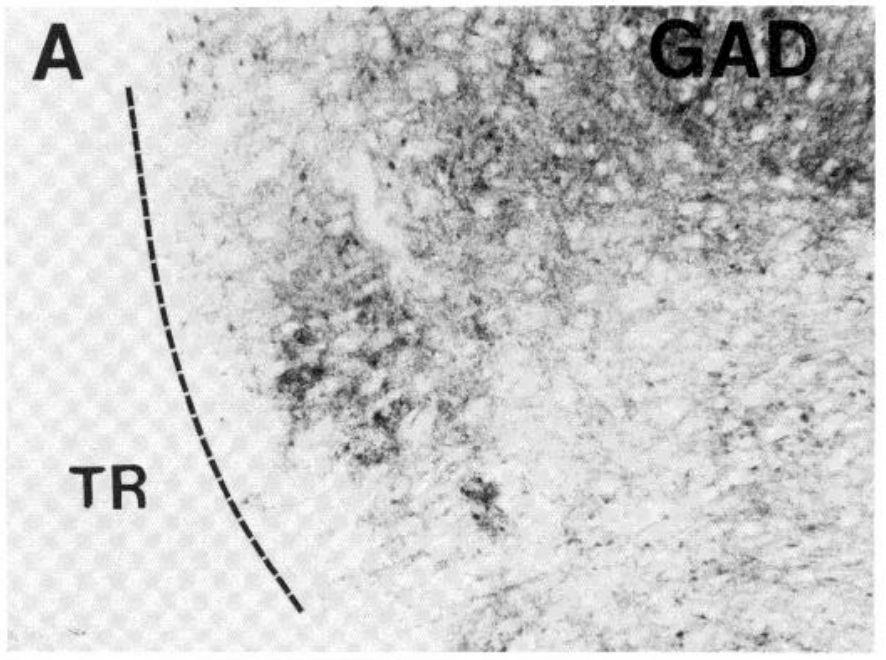

B

NSS

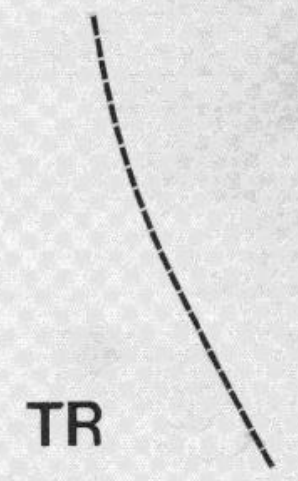

Figure 2. A, Photomicrograph of a vibratome section through the ventral posterior nucleus of Galago corresponding to the area indicated by the markers in Figure $1 B$. This section was incubated with GAD antiplasma. The lateral boundary of the ventral posterior nucleus with the thalamic radiations $(T R)$ is indicated. $B$, Photomicrograph of a vibratome section adjacent to the section shown in $A$ and incubated in pre-immune plasma as a control. The dashed line indicates the lateral boundary of the ventral posterior nucleus with the thalamic radiations.

This color photomicrograph illustrates the striking contrast in size between the small, brown GAD-immunoreactive cells and the larger, GAD-negative Nissl-stained neurons.

By drawing, counting, and measuring every GADimmunoreactive and non-GAD Nissl-stained neuron in a rectangular sample area, it was possible to estimate the size and relative proportion of GAD-immunoreactive and non-GAD neurons. The principal results are, first, that GAD-immunoreactive neurons are small and, second, that they consistently make up about $30 \%$ of the neurons in samples from the ventral posterior nucleus of both Galago and cat. Figures 4 and 5 show in histogram form the distribution of sizes of GAD-immunoreactive and non-GAD Nissl-stained neurons obtained from sample $2412 \mathrm{~B}$ in the cat and sample 2376A in Galago. In the cat, the GAD-immunoreactive neurons have a mean cell body area of $109 \mu \mathrm{m}^{2}$ and are significantly smaller than the non-GAD Nissl-stained neurons within the same section, whose mean area is $252 \mu \mathrm{m}^{2}$ (median test, $\mathrm{X}^{2}=41, d f=$ $1, p<1 \times 10^{-7}$ ). GAD-immunoreactive neurons make up $29 \%$ of the total sample. In Galago (sample 2376A) GADimmunoreactive neurons are also significantly smaller, with a mean cell body area of $80 \mu \mathrm{m}^{2}$, and the non-GAD Nissl-stained cells from the same sample area are larger, with a mean cell body size of $184 \mu \mathrm{m}^{2}$ (median test, $\mathrm{X}^{2}$ $=48, d f=1, p<1 \times 10^{-7}$ ). The GAD-immunoreactive neurons make up $32 \%$ of the total. In both the cat and Galago the distribution of sizes of GAD-immunoreactive neurons and non-GAD Nissl-stained neurons overlap; not all small neurons are GAD immunoreactive.

In order to show that the difference in size between the GAD-immunoreactive neurons and the non-GAD Nissl-stained neurons is reliable, we took samples from a number of animals. Table I shows the results of all measurements of neurons in the cat and Galago and the standard errors of each group of means $\left(\mathrm{SD}_{\overline{\mathrm{x}}}\right) . \mathrm{GAD}$ percentages are only shown for counterstained material. The mean sizes of GAD-immunoreactive neurons in samples of the ventral posterior nucleus of the cat range from 109 to $152 \mu \mathrm{m}^{2}$ and in Galago range from 80 to 102 $\mu \mathrm{m}^{2}$. In contrast, the mean sizes of Nissl-stained neurons in the ventral posterior nucleus range from 252 to 308 $\mu \mathrm{m}^{2}$ in the cat and from 178 to $198 \mu \mathrm{m}^{2}$ in Galago. These values for average sizes of Nissl-stained neurons in the cat are somewhat smaller than those we have reported previously (Penny et al., 1982a). We attribute this result to differences in methods of fixation and tissue processing used in the two studies.

We have also examined the distribution of GAD immunoreactivity in another portion of the somatosensory thalamus, the anterior division of the posterior complex of Rose and Woolsey (1958). Our samples were taken from a region which is lateral to the ventral posterior nucleus and medial to the lateral geniculate and which is thought to receive input from the spinothalamic tract (Poggio and Mountcastle, 1960; Boive, 1971; Jones and Burton, 1974; Berkley, 1980; Pearson and Haines, 1980a). Although the cells of this region are smaller on the average than those in the ventral posterior nucleus, the GAD-immunoreactive neurons still constitute a distinct population based on their size, as shown by the distributions in Figures 6 and 7. In the cat GAD-immunoreactive cells have a mean soma area of $94 \mu \mathrm{m}^{2}$ and are again smaller than non-GAD cells, which have a mean soma area of $198 \mu \mathrm{m}^{2}$. In Galago the average size of GAD-immunoreactive neurons in $93 \mu \mathrm{m}^{2}$ and of Nisslstained neurons that lack GAD label is $179 \mu \mathrm{m}^{2}$. The percentage of GAD-immunoreactive neurons in our samples of the posterior group $(41,41$, and $35 \%)$ is significantly greater than that found in the ventral posterior nucleus (Mann-Whitney $U$ test, $\mathrm{Z}=2.34, p<0.01$ ).

Double labeling for GAD immunoreactivity and retrograde transport of HRP from somatosensory cortex. In the next series of experiments we asked whether any of the GAD-immunoreactive neurons in the ventral posterior nucleus project to the cerebral cortex. In four animals, we injected HRP in the somatosensory cortex and processed the resulting sections for the presence of transported HRP and GAD immunoreactivity. In no case were 


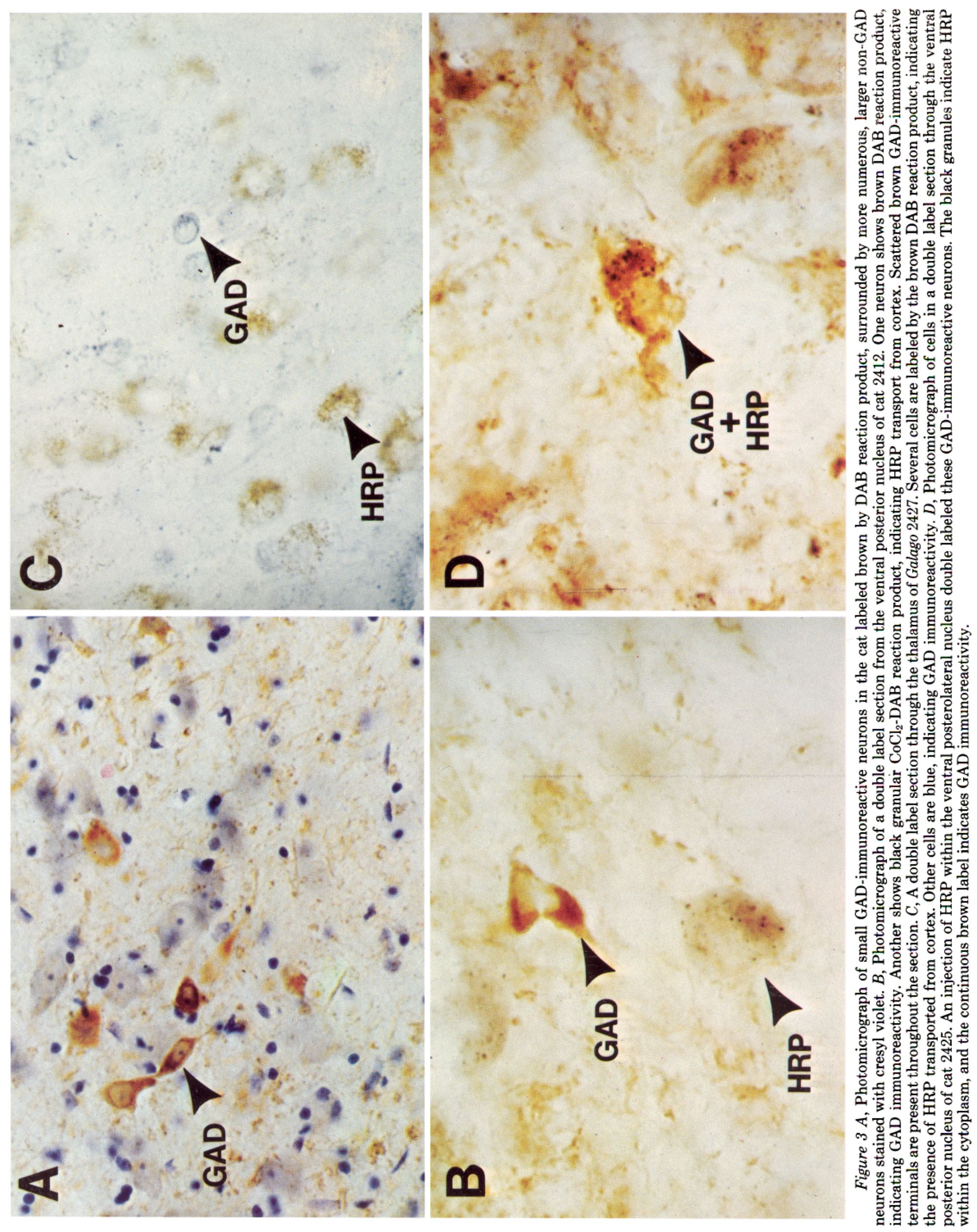


we able to demonstrate a cell labeled for both the presence of HRP and GAD immunoreactivity.

The previous section compared $\mathrm{GAD}$-immunoreactive cells with non-GAD neurons stained with cresyl violet. The experiments described here offer the chance to com-

\section{B Cat VPL}
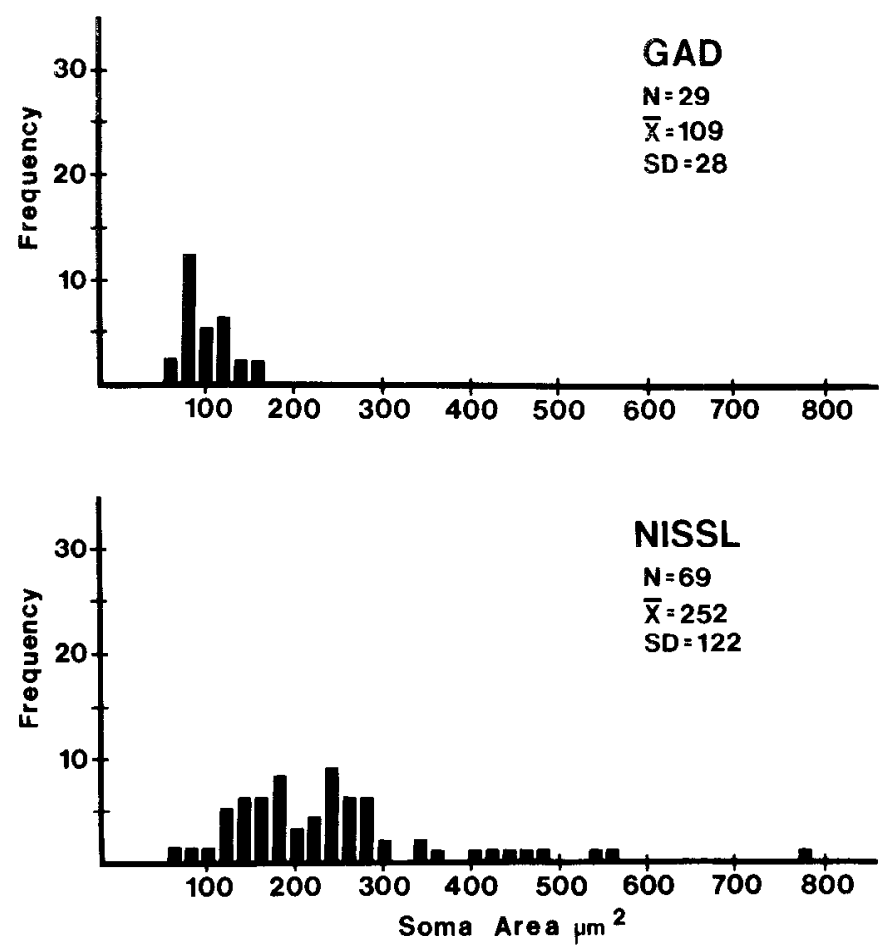

Figure 4. Histograms showing the distributions of cell body areas in square micrometers of GAD-immunoreactive and nonGAD Nissl-stained neurons from a $0.26-\mathrm{mm}^{2}$ sample of cat 2412 ventral posterior nucleus ( $V P L$ ).

\section{A Galago VPL}
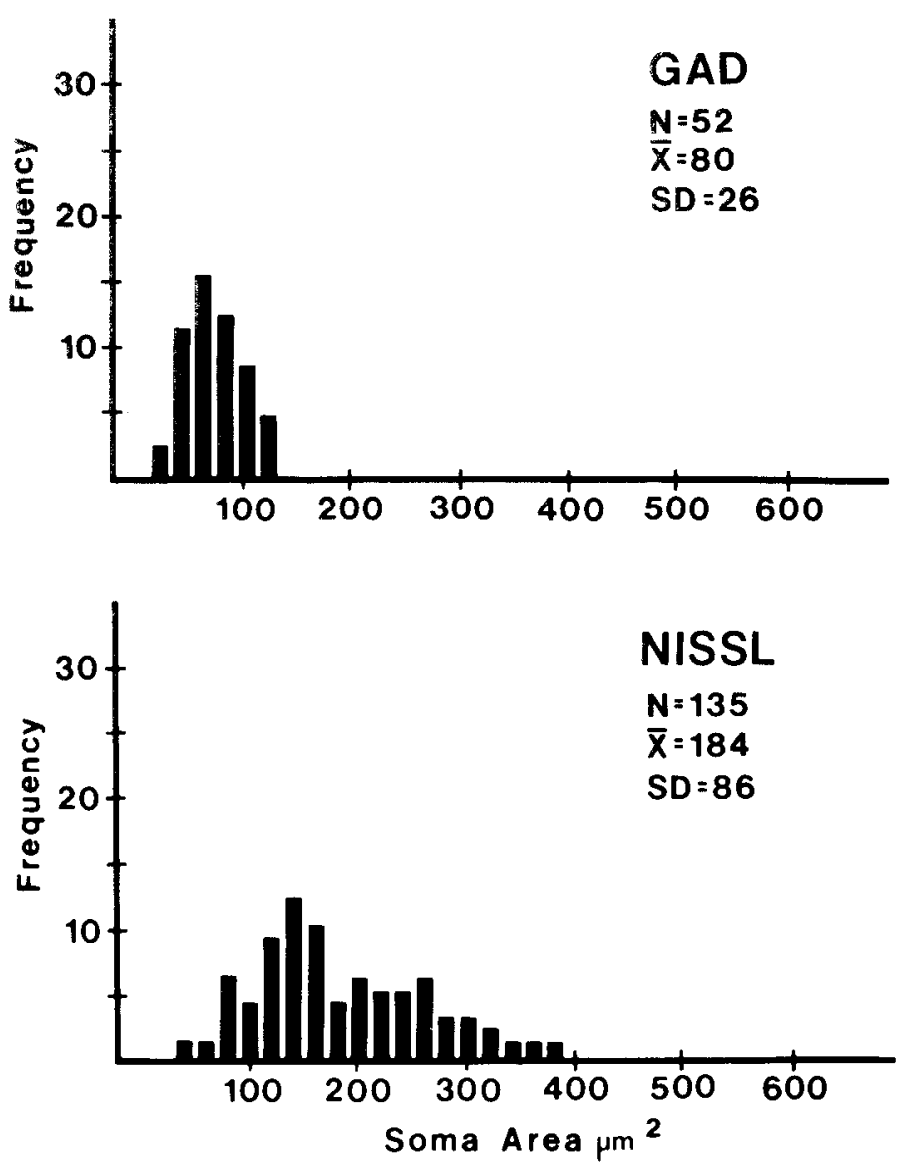

Figure 5. Histograms showing the distributions of cell body areas in square micrometers of GAD-immunoreactive and nonGAD Nissl-stained neurons from a $0.16-\mathrm{mm}^{2}$ sample of Galago 2376 ventral posterior nucleus $(V P L)$.

TABLE I

Cell soma sizes of samples of GAD-positive, HRP-labeled, and Nissl-stained cells

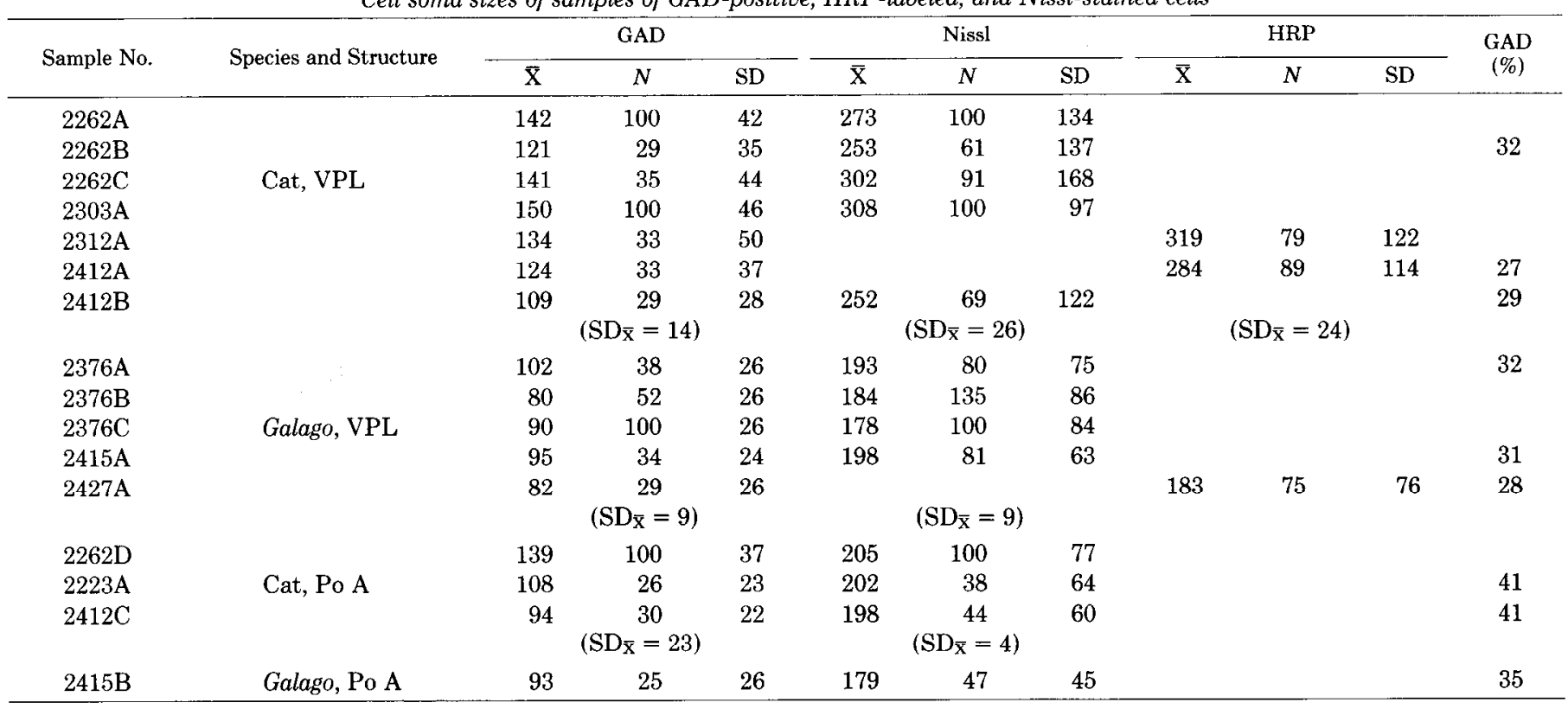


2412C Cat PoA
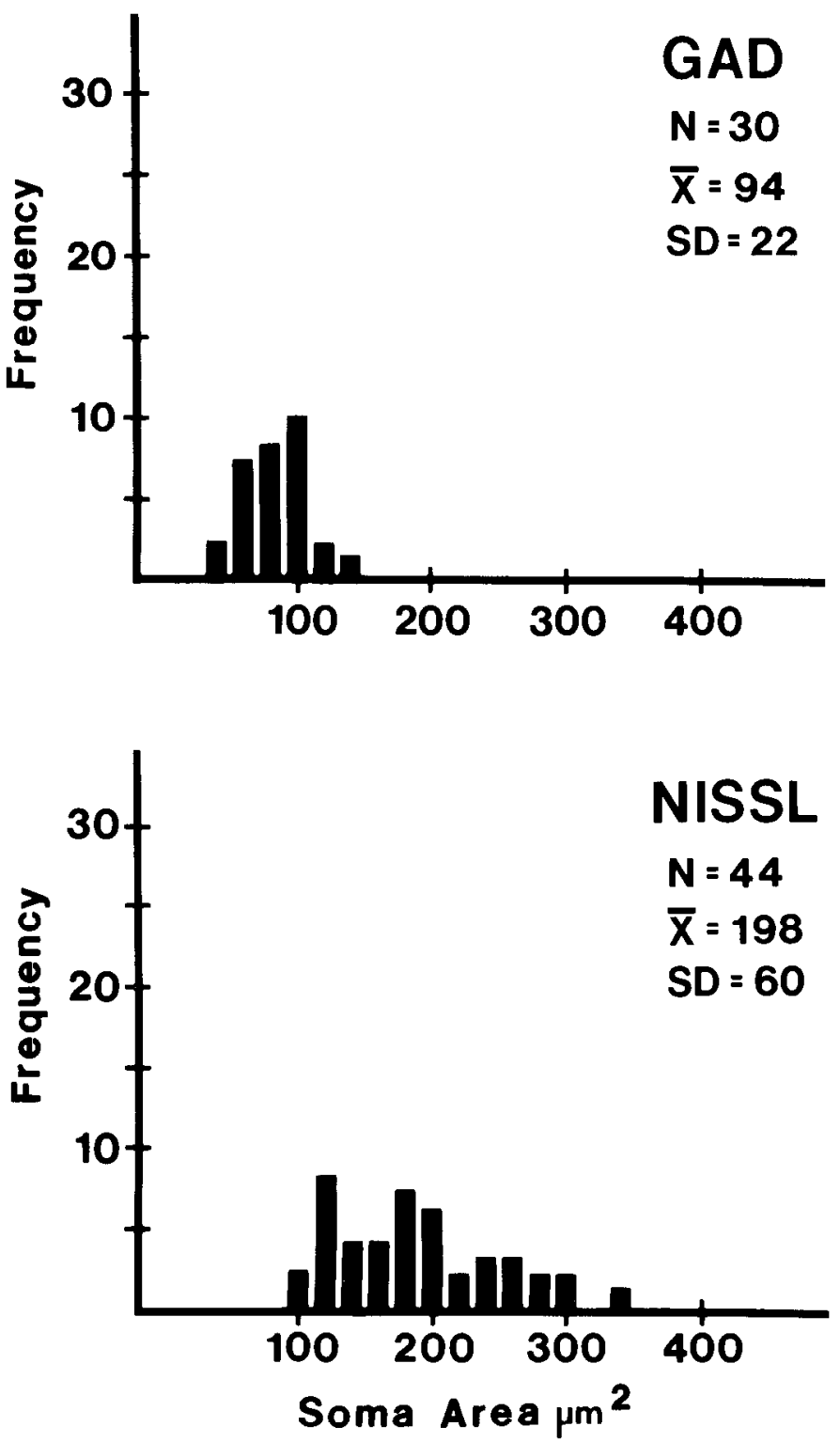

Figure 6. Histograms showing the distributions of cell body areas in square micrometers of GAD-immunoreaclive and nonGAD Nissl-stained neurons obtained from a $0.26-\mathrm{mm}^{2}$ sample of the anterior division of the posterior group $(P O A)$ in cat 2412 .

pare GAD-immunoreactive cells with cells labeled by transported HRP. The principal results are: (1) that every neuron revealed by the cresyl violet stain is either GAD positive or HRP positive; (2) that the size and proportion of the GAD-immunoreactive neurons in this material match those measurements of GAD-immunoreactive neurons labeled in the "single label" experiments; and (3) that the size and proportion of the HRP- labeled neurons match those measurements of non-GAD Nissl-stained neurons in the "single label" experiments.

Examples of these cells in sections photographed prior to counterstaining are shown in Figure $3, B$ and $C$. In Figure $3 B$ are shown small, dark brown DAB-labeled GAD-immunoreactive neurons and larger, granular black $\mathrm{CoCl}_{2}$-DAB-labeled projection neurons in the cat. Shown in Figure $3 \mathrm{C}$ is material from Galago processed by a second method. GAD-immunoreactive neurons are la-

\section{B Galago PoA}
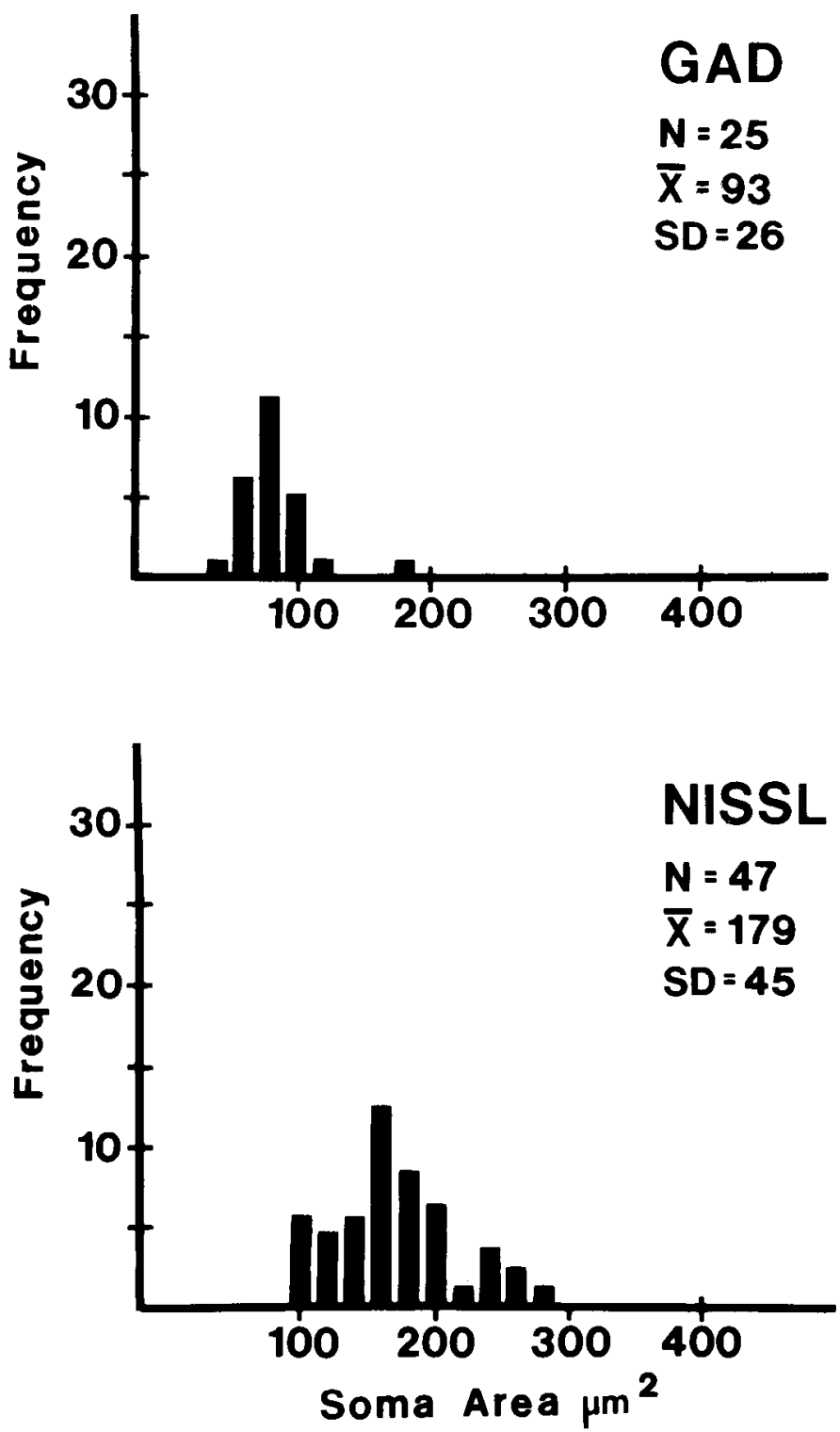

Figure 7. Histograms showing the distributions of cell body areas in square micrometers of GAD-immunoreactive and nonGAD Nissl-stained neurons obtained from a $0.16-\mathrm{mm}^{2}$ sample of the anterior division of the posterior group $\left(P_{O} A\right)$ in Galago 2415. 
beled by the blue 4-chloro-1-naphthol reaction product, and neurons containing transported HRP are labeled by the brown $\mathrm{DAB}$ reaction product.

From both cat 2412 and Galago 2427 we took rectangular sample areas from the region of the medial division of the ventral posterolateral nucleus containing labeled HRP cells. In each of these samples every neuron identified by the presence of both a cresyl violet-stained Nissl substance and nucleolus contained either the brown DAB marker for the presence of GAD immunoreactivity or the granular black marker for the presence of transported HRP, but no cell contained both.

Figure 8 shows the distribution of sizes of GAD-immunoreactive and HRP-labeled neurons from a $0.26 \mathrm{~mm}^{2}$ sample in cat 2412. The mean size of GAD-immunoreactive neurons is $124 \mu \mathrm{m}^{2}$, and the mean size of HRPcontaining neurons is $284 \mu \mathrm{m}^{2}$. This difference is significant (median test, $\mathrm{X}^{2}=40, d f=1, p<1 \times 10^{-7}$ ). The GAD-immunoreactive neurons make up $27 \%$ of the total.

\section{A Cat VPL}
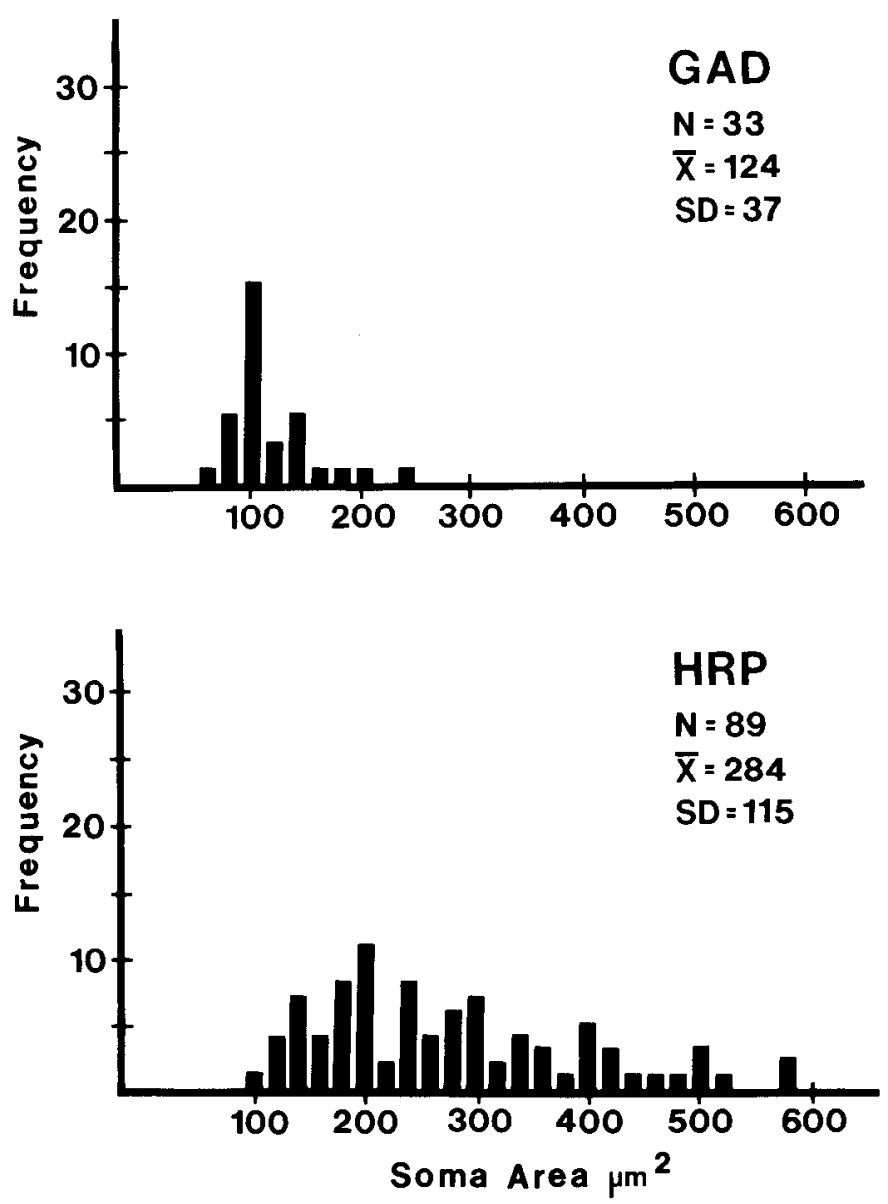

Figure 8. Histograms showing the distributions of cell body areas in square micrometers of GAD-immunoreactive and nonGAD HRP-labeled projection neurons obtained from a 0.26 $\mathrm{mm}^{2}$ sample of cat 2412 ventral posterior nucleus (VPL).

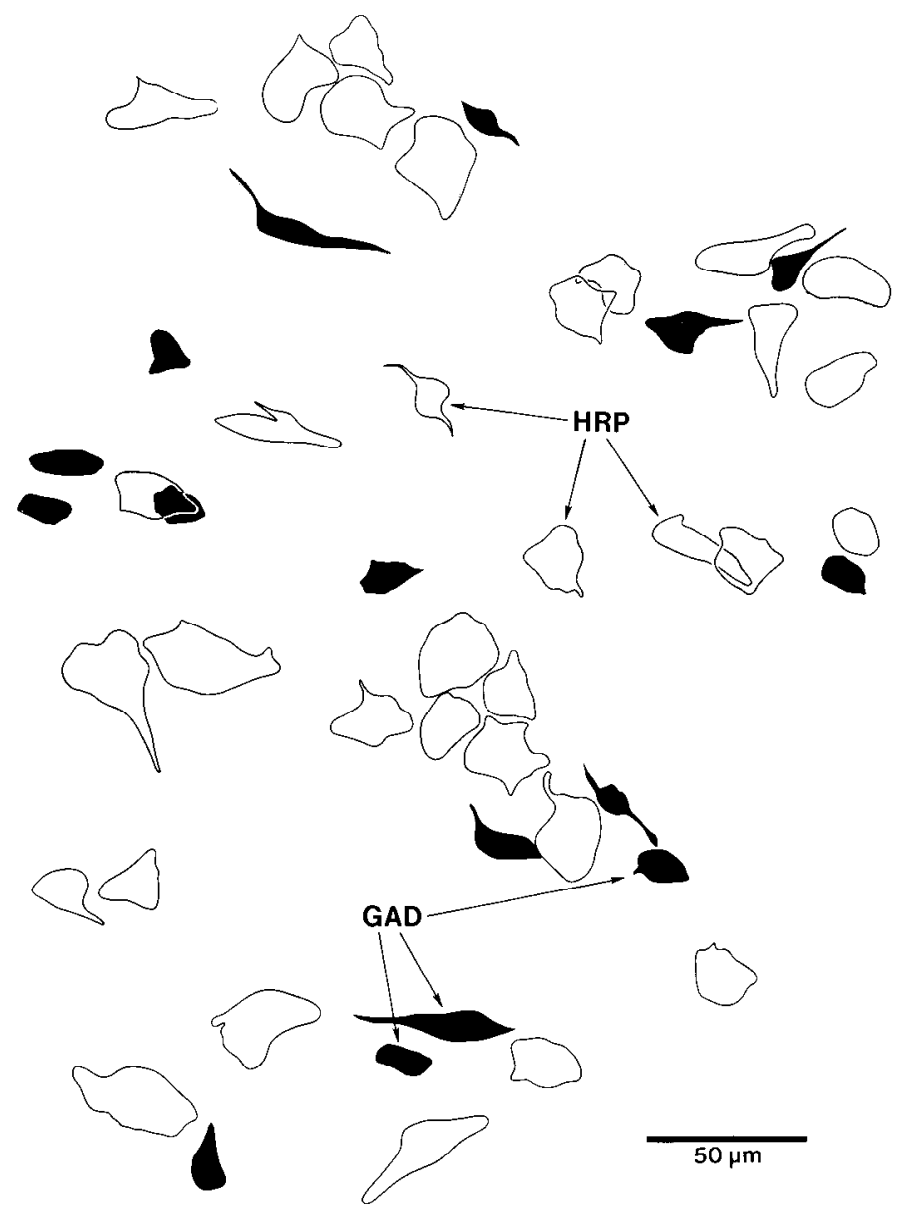

Figure 9. Drawing of HRP-labeled neurons (shown in while) and smaller GAD-labeled neurons (shown in black) from a portion of sample 2412 of a double label section from cat ventral posterior nucleus.

As shown in Figure 9, which is a drawing taken from this sample, the GAD-immunoreactive neurons are smaller than the HRP-labeled neurons and make up about onethird of the neurons in the region. The distribution of cell body sizes of GAD-immunoreactive and HRP-labeled neurons in a sample area of $0.16 \mathrm{~mm}^{2}$ in Galago 2427 is shown in Figure 10. The GAD-containing neurons, with a mean size of $82 \mu \mathrm{m}^{2}$, are significantly smaller than the HRP-labeled neurons, whose mean size is $183 \mu \mathrm{m}^{2}$ (median test, $\mathrm{X}^{2}=38, d f=1, p<1 \times 10^{-7}$ ). Every cell revealed by the cresyl violet stain contained either GAD label or HRP label, and no cell contained both.

Double label for GAD immunoreactivity and local uptake of HRP within the ventral posterior nucleus. The failure to find cells labeled for both GAD immunoreactivity and HRP transport could mean that the two labeling methods are somehow incompatible. To rule out this possibility and to show that the double labeling methods are in principle able to show the presence of both HRP and GAD immunoreactivity within a single cell, we injected HRP directly into the ventral posterior nucleus of cat 2425. This injection resulted in local uptake of HRP by the GAD-immunoreactive neurons, as illustrated by Figure $3 D$. This photomicrograph shows a dark brown GAD- 


\section{A Galago VPL}
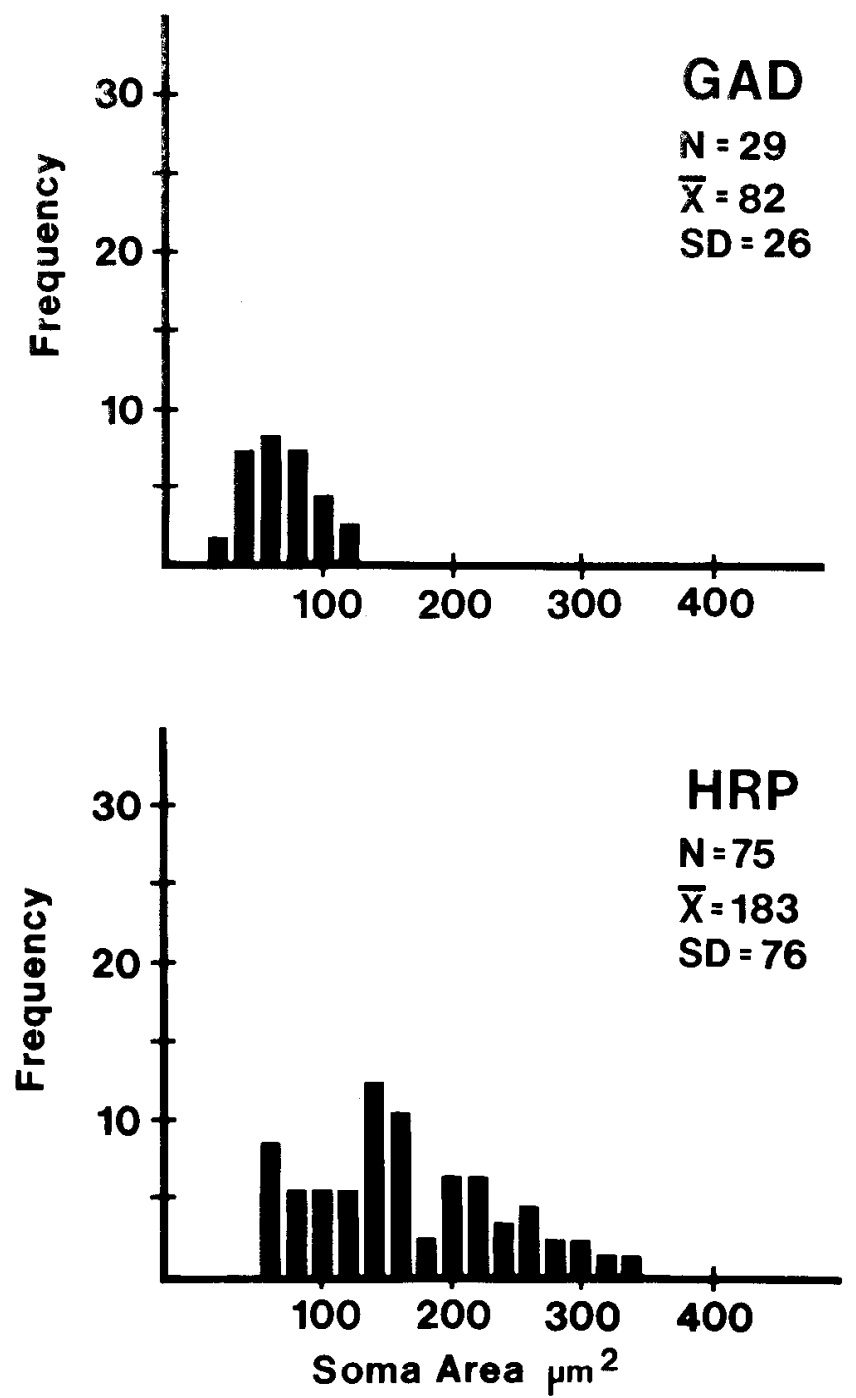

Figure 10. Histograms showing the distributions of cell body areas in square micrometers of GAD-immunoreactive and nonGAD HRP-labeled projection neurons obtained from a 0.16 $\mathrm{mm}^{2}$ sample taken from Galago 2427 ventral posterior nucleus $(V P L)$.

immunoreactive neuron also displaying the granular black label indicating HRP transport. Neurons in the perigeniculate nucleus of the thalamus can also be double labeled for HRP retrogradely transported from the lateral geniculate nucleus as well as for GAD immunoreactivity (to be reported in a later publication).

Morphology of GAD-immunoreactive neurons. The GAD-immunoreactive neurons not only are similar in size, but also have characteristic shapes and dendritic features. As shown by the drawings in Figure 11 and the photographs in Figure 12, the GAD-immunoreactive neurons in the cat display ovoid or fusiform cell bodies and few primary processes (usually two to four), each of which is relatively thick. On some neurons fine processes are found branching from the primary ones in broomstick-like arrays. Processes may travel for considerable distances and occasionally display regularly spaced beads along their length. The GAD-immunoreactive neurons in the Galago have similar characteristics, as shown by the drawings and photomicrographs in Figures 13 and 14. It must be emphasized that the finer secondary or tertiary processes of the GAD-immunoreactive neurons are difficult to draw based on immunocytochemical material, and that the drawings in Figures 11 and 13 made no attempt to trace the dendrites to their ultimate termination.

In the cat round clusters containing 5 to more than 20 GAD-immunoreactive terminals are distributed throughout the ventral posterior nucleus as shown in Figure 15A. Each cluster is typically 1 to $8 \mu \mathrm{m}$ in diameter. That these clusters are not seen in the posterior nuclear group of cat or the ventral posterior nucleus of Galago is shown by Figure 15, $B$ and $C$. Examples of terminal clusters are shown at higher power in Figure $16, A$ and $B$. Close examination of the clusters reveals that they are sprays of terminals associated with the dendrites of the GADimmunoreactive neurons. Many GAD-immunoreactive

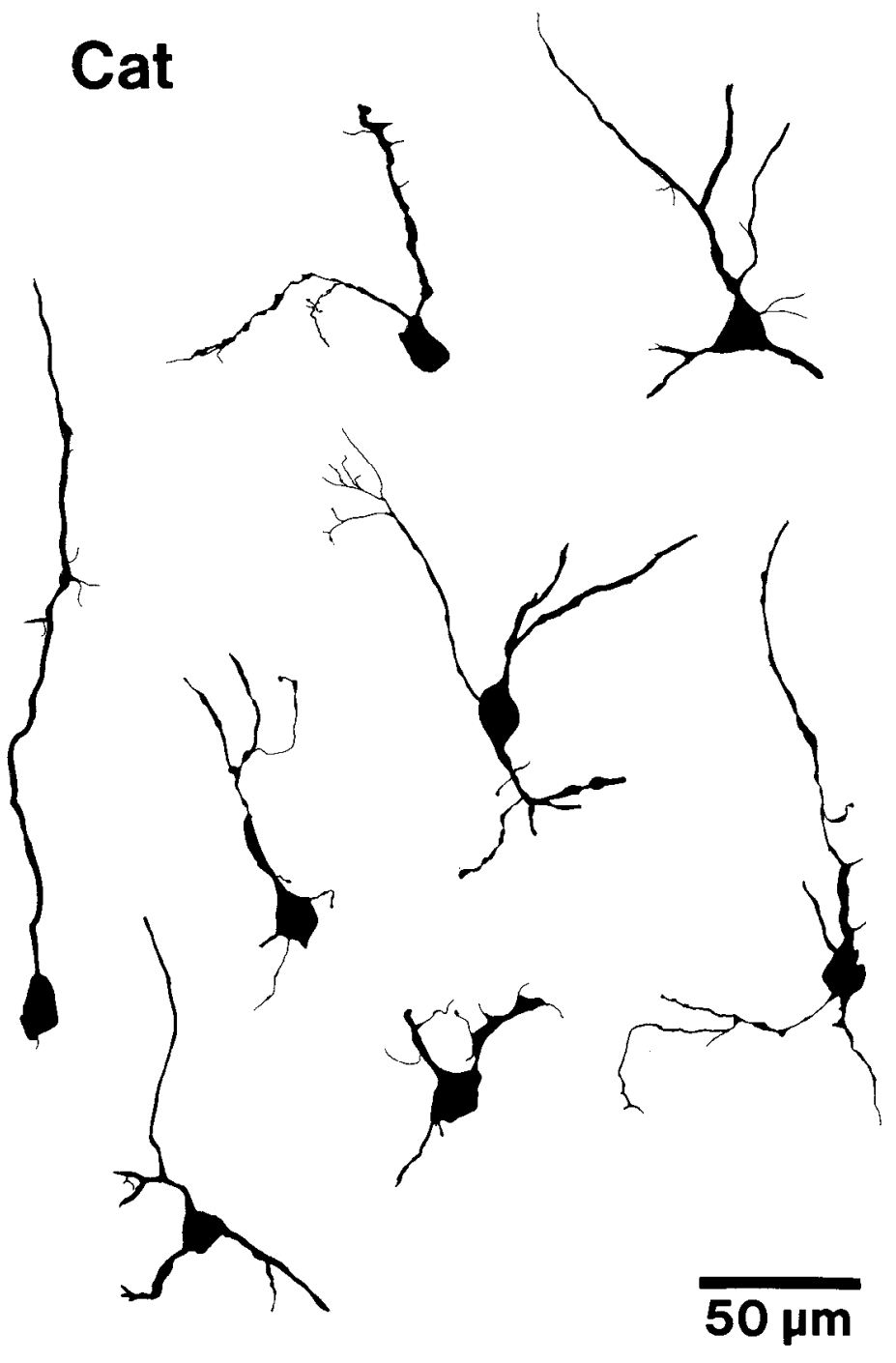

Figure 11. Drawings of the cellular morphology of some GAD-immunoreactive neurons in cat ventral posterior nucleus. 

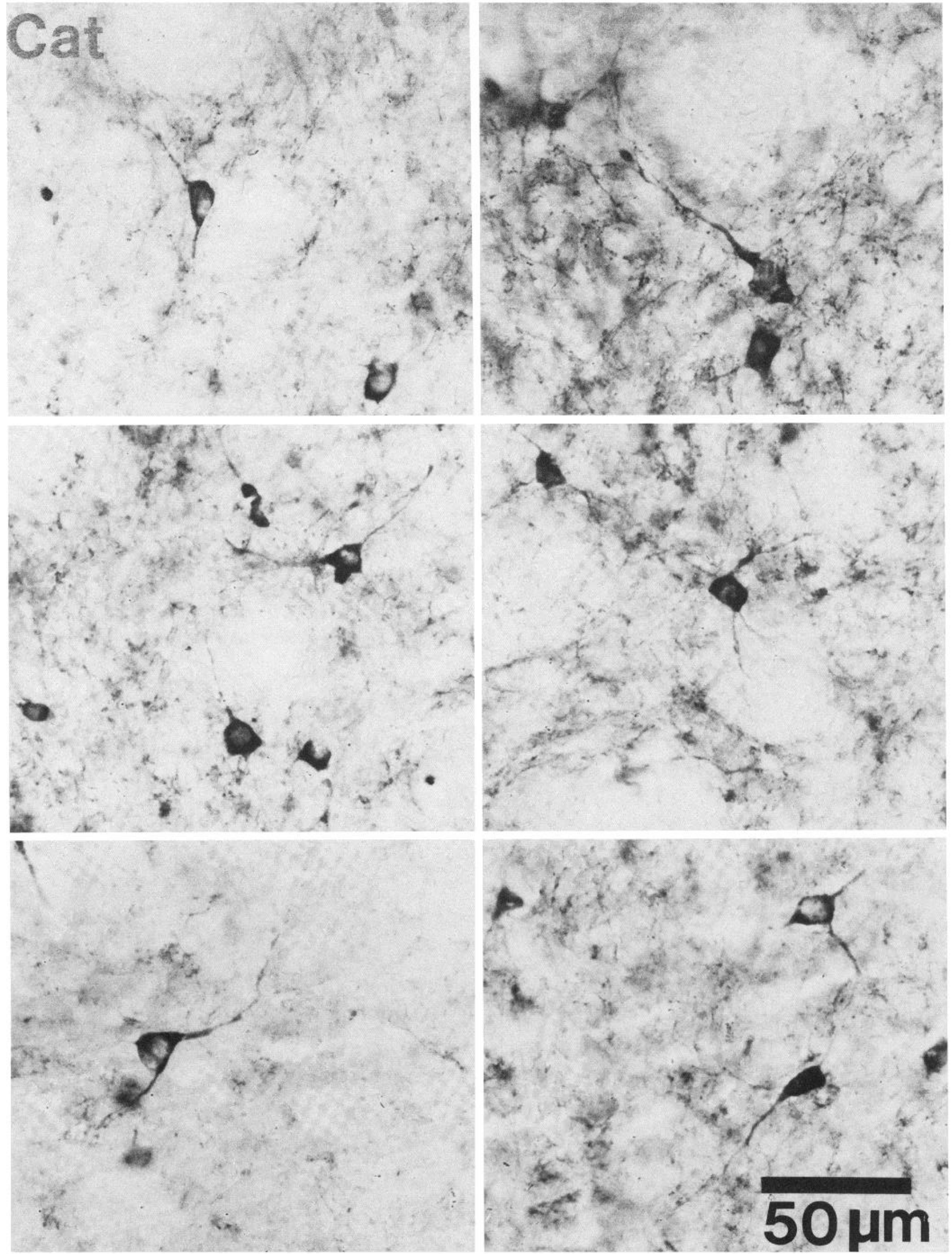

Figure 12. Photomicrographs of some GAD-immunoreactive neurons in the ventral posterior nucleus of the cat. 


\section{Galago}

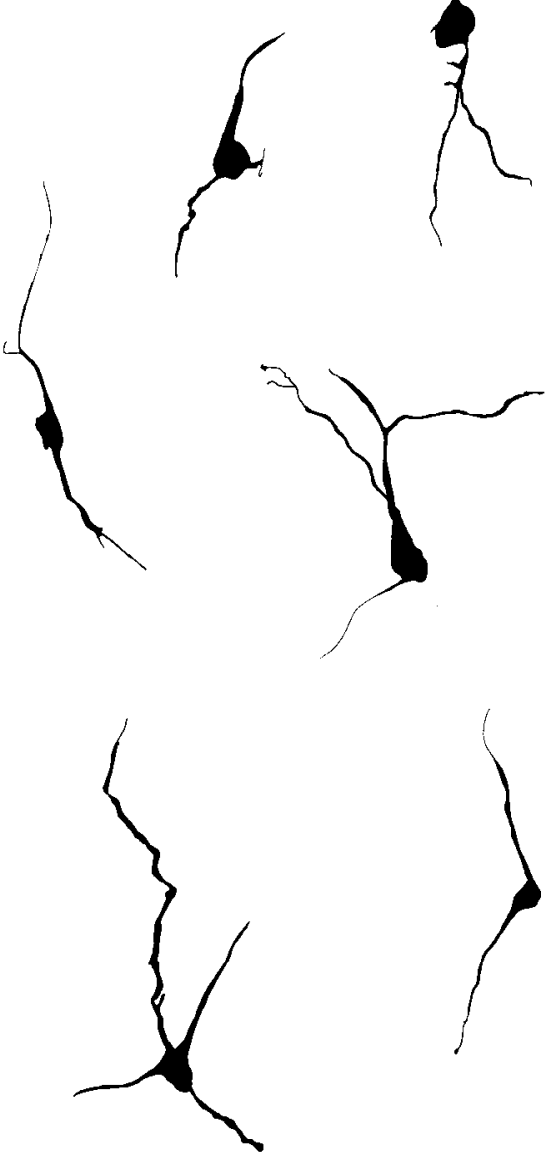

Figure 13. Drawings of the cellular morphology of some G $\Lambda \mathrm{D}$-immunoreactive neurons in Galago ventral posterior nucleus.

dendrites seem to break into one of these sprays at their distal ends, as indicated by arrows in Figure 16, $C$ and $D$. The short processes connecting the terminals with the dendrites are very fine, almost at the limit of resolution, but occasionally one can be visualized. Examination of the distribution of the terminal clusters in the cat reveals that they are confined to only certain thalamic subdivisions, and these subdivisions correspond to regions where the terminal labeling is most dense (see Fig. 1). Hence these clusters are found in the ventral posterior nucleus, the lateral geniculate nucleus, the medial geniculate nucleus, the pulvinar nucleus, and the rostrallateralmost subdivision of the central lateral nucleus, but not elsewhere.

Round terminals attached by short fine processes to the dendrites of GAD-immunoreactive neurons are also seen in Galago, but in this species the terminals are not gathered in sprays or clusters. Two such terminals and short processes are shown in Figure $16 E$, indicated by arrows. The primary dendrites of the GAD-immunoreactive neurons also display prominent varicosities, and examples of these are indicated by arrows in Figure $16 F$.
GAD-immunoreactive terminals are also seen covering the cell somas and proximal dendrites of non-GAD Nisslstained neurons as shown in Figure 17. We have not found cases in which these terminals obviously arise from the dendrites of GAD-immunoreactive neurons.

Morphology of projection neurons and comparison with GAD-immunoreactive neurons. To compare the morphology of GAD-immunoreactive neurons with that of projection neurons, we made massive injections of HRP into the primary somatosensory cortex and underlying white matter of two cats and reacted the resultant 100$\mu \mathrm{m}$ thalamic sections for the presence of transported HRP. This procedure produced good filling of cell bodies and dendrites of thalamic relay neurons in the ventral posterolateral nucleus, allowing them to be compared with the GAD-immunoreactive neurons. Of course, the dissemblance of HRP-filled projection neurons must be interpreted with some caution; the differences may arise from method rather than structure. In particular, because it is difficult to trace and draw fine branches of the GADimmunoreactive processes, we confine our comparison to the cell body shapes and proximal dendrites.

Shown in Figures 18, 19, and 20 are drawings of typical HRP-labeled projection cells, arranged according to increasing cell body area. The cell body size in square micrometers of each neuron is indicated. Clearly, cell body size is related to morphology. The smallest neurons, shown in Figure 18, range in size from less than $100 \mu \mathrm{m}^{2}$ to greater than $200 \mu \mathrm{m}^{2}$ and have ovoid or fusiform cell bodies. They are in the size range of GAD-immunoreactive neurons, but unlike GAD neurons they display four to eight labeled primary dendrites, many of which are quite thin. Small projection cells lack the thicker primary processes characteristic of the GAD-immunoreactive neurons and display no varicosities. Based on their size and cell body shape, the smallest projection neurons are very likely the same as those we earlier identified as having projections to the superficial layers of the somatic cortex (Penny et al., 1982a).

In Figure 19 are shown examples of the medium-sized projection neurons of the cat. The medium-sized neurons, which range from about 200 to $350 \mu \mathrm{m}^{2}$ in size, are the most numerous projection neurons in the ventral posterior nucleus (see, for example, Fig. 8). They display a greater number of primary dendrites (6 to 12) than do the GAD-immunoreactive neurons or the small projection neurons, and they arborize over a wider area than either class. Although the medium-sized neurons vary more in shape than neurons of other sizes, at least two principal forms can be identified. The first has an elongate or fusiform cell body and a restricted, bipolar dendritic arborization. Examples of fusiform cells are shown in Figure 19; their soma areas are 200, 270, and $290 \mu \mathrm{m}^{2}$. A second form is characterized by round cell bodies and radiate dendritic arborizations. Examples of round cells are also shown in Figure 19; their soma areas are 250, 260 , and $260 \mu \mathrm{m}^{2}$. Other neurons can be found with medium cell sizes which are between these two forms or which have unusual morphologies.

Neurons with somas larger than $350 \mu \mathrm{m}^{2}$ make up about $25 \%$ of the projection cells in the ventral posterior nucleus of the cat. The large neurons, samples of which 


\section{Galago}
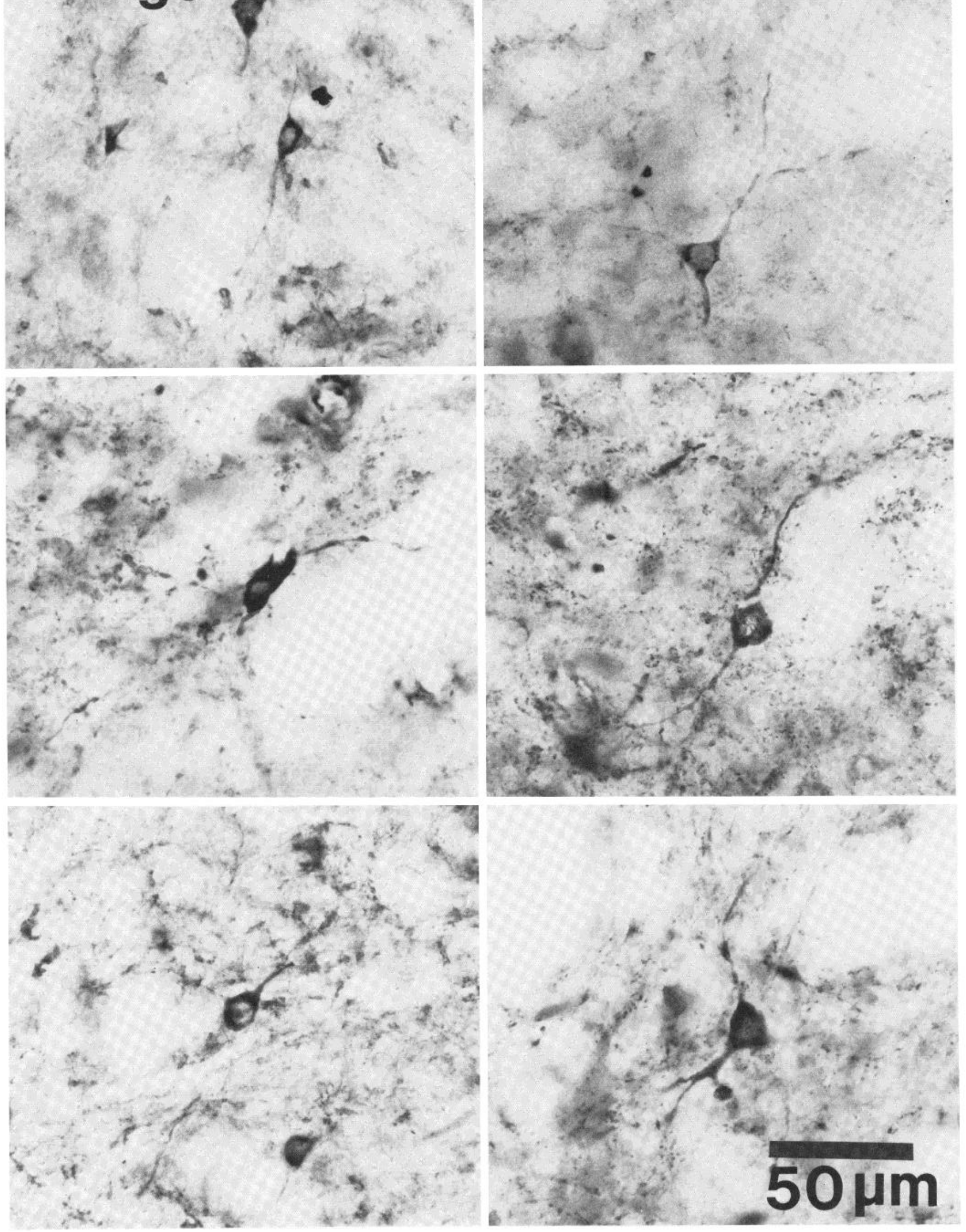

Figure 14. Photomicrographs of some GAD-immunoreactive neurons in the ventral posterior nucleus of Galago. 

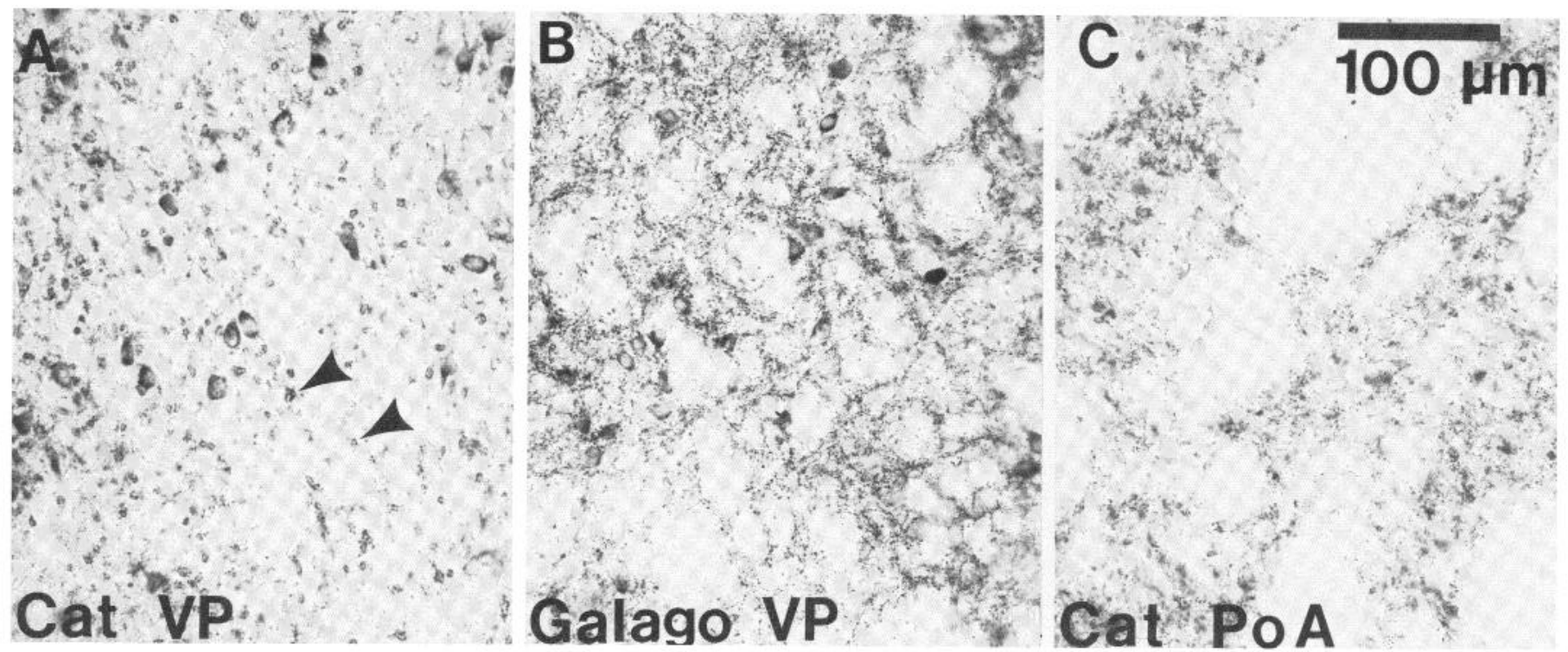

Figure 15. A, Photomicrograph illustrating the prominent round GAD terminal clusters in the ventral posterior (VP) nucleus of the cat. $B$ and $C$, Photomicrographs illustrating that the GAD terminals in the ventral posterior nucleus of the Galago and in the anterior division of the posterior group $(P o A)$ of the cat are not aggregated in clusters.

are shown in Figure 20, have large round or multipolar cell bodies and many thick primary dendrites which arborize in a radiate pattern over considerable distances. The largest neurons in the class display the widest arborizations. Although large cells do not vary in morphology to as great a degree as do the cells of medium size, an occasional unusual cell is found. An example is shown in Figure 20, and it has a cell soma area of $430 \mu \mathrm{m}^{2}$. The projection neurons tend to have their primary axes of dendritic orientation roughly parallel to the dorsoventral plane. This direction of elongation is in the same plane as the elongated rods formed by the arborizations of the lemniscal afferents (Jones and Friedman, 1981).

\section{Discussion}

The principal findings are, first, that a constant large proportion of neurons (about $30 \%$ ) in the ventral posterior nucleus of the cat and Galago are immunoreactive with antisera to glutamic acid decarboxylase. Because GAD immunoreactivity is an established marker for GABAergic neurons, these neurons are probably GABAergic (e.g., McLaughlin et al., 1974). Second, the GAD-immunoreactive neurons form a distinct class on grounds of their small cell body size and their dendritic morphology. Third, GAD-immunoreactive neurons are not labeled by HRP transported from the somatosensory cortex, a finding that suggests that these neurons have only local connections. Fourth, the neurons which are filled by retrograde transport of HRP from the somatosensory cortex have a wide range of morphologies, but all of these differ from the morphology of the GAD-immunoreactive neurons. Fifth, we find that among the projection neurons, dendritic morphology is related to cell body size.

These results, taken together, support the old ideas that, first, there are two principal classes of thalamic neurons, local circuit neurons and projection neurons, and, second, that the role of local circuit neurons is to modulate the function of projection neurons by some inhibitory influence. Whether the argument has merit will now be discussed.

The distinction between local circuit neurons and projection neurons in the thalamus goes back to Ramón y Cajal $(1909,1966)$, who described thalamic neurons with short axons. Since the time of Ramón y Cajal a number of studies using the Golgi method to classify cell types found support for the existence of local circuit neurons in the thalamus. For example, Guillery (1966) described a local axon neuron (class 3) in the lateral geniculate nucleus.

Turning to the ventral posterior nucleus in particular, several authors have argued on various grounds that local circuit neurons can be identified in Golgi material (Tömböl, 1967; Pearson and Haines, 1980b; Spreafico et al., 1983). The advent of the electron microscope offered new opportunities to identify neurons with local connections and, based on the use of this method, certain presynaptic dendritic specializations have been attributed to local circuit neurons (Ralston and Herman, 1968; Ralston, 1971a, b; Famiglietti and Peters, 1972).

Still, it is difficult to demonstrate by the Golgi method or by any method that a neuron does not project; a cell might have a short axon branch and a projection axon branch as well. For example, the medium spiny cells of the neostriatum were thought to be local circuit neurons because of their locally arborizing axons (Fox et al., 1971; Kemp and Powell, 1971), but recent studies exploiting the intracellular injection of HRP have revealed that these neurons do have local axonal branches within the neostriatum, but they also have axonal branches to the globus pallidus and substantia nigra (Preston et al., 1980). Closer to the subject of our study is the Golgi analysis of the ventral posterior nucleus showing cells that have local axonal branches (Tömböl, 1967). For our purpose the point is that these cells have a size and overall morphology that suits our picture of a projection neuron as defined by retrograde filling by HRP. 

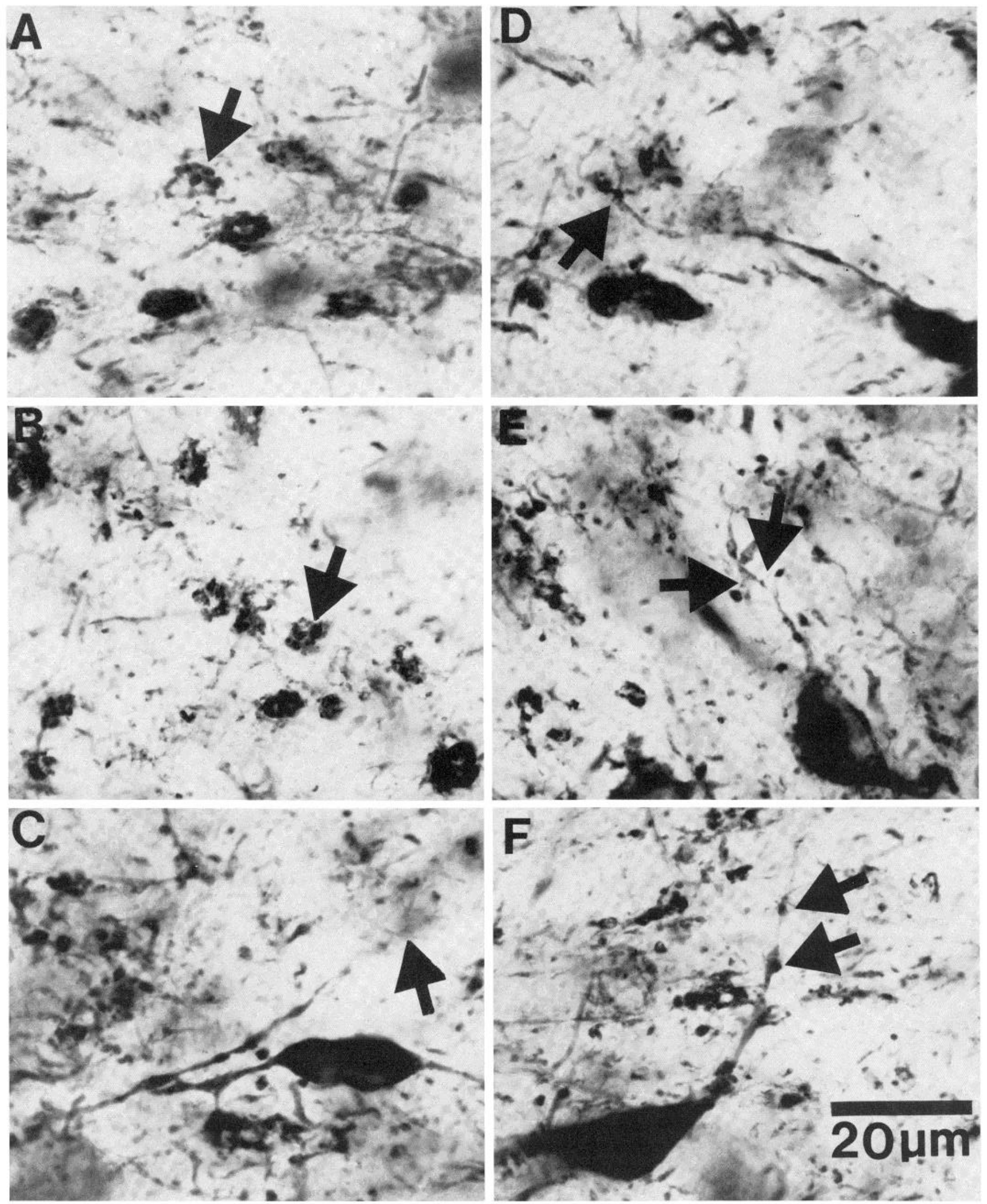

Figure 16. $A$ and $B$, High power photomicrographs of numerous clusters of GAD-immunoreactive dendritic terminals in the ventral posterior nucleus of the cat. $C$ and $D$, Dendritic processes of GAD-immunoreactive cells breaking up into clusters of dendritic terminals in the ventral posterior nucleus of the cat. Arrows indicate the clusters. Some of these dendrites display prominent varicosities. $E$, Two dendritic terminals with visible stalks connecting them to a dendrite of a GAD-immunoreactive cell in Galago. F, Two prominent varicosities (indicated by arrows) on a dendrite of a GAD-immunoreactive neuron in Galago. 
The HRP transport method provides an obvious test of the presence of thalamic neurons that do not project to somatosensory cortex. If there are local circuit neurons at all in any circumscribed area of the ventral posterior nucleus, then a good number of unlabeled neurons should be found dispersed among neurons labeled by retrograde transport of HRP from somatosensory cortex. As it turns out, surprisingly few unlabeled cells are found in the ventral posterior nucleus of the cat after large HRP injections in cortical area SI (Saporta and Kruger, 1979). Of course, it is possible that the local circuit neurons are just missed in Nissl stain-for example, they might be

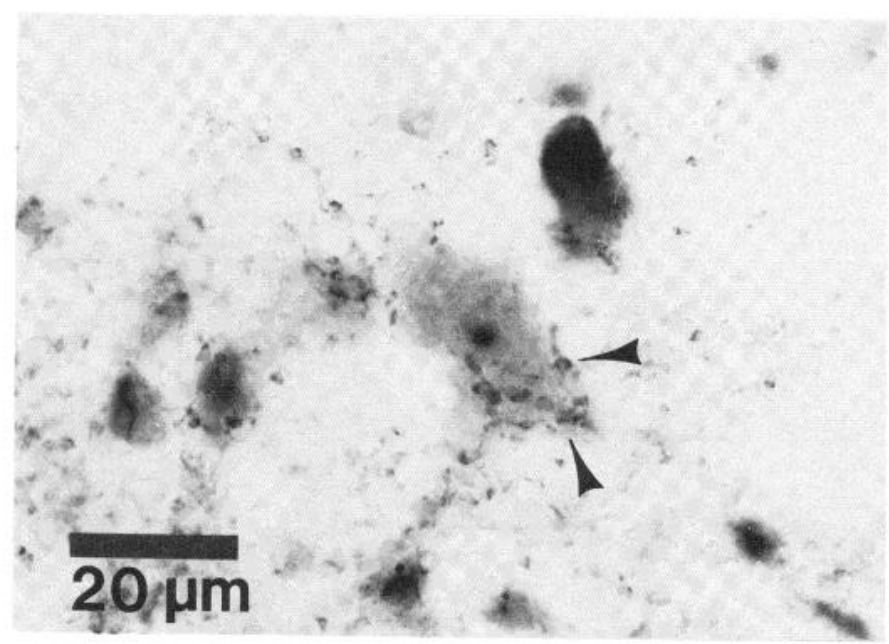

Figure 17. A non-GAD-immunoreactive neuron stained with cresyl violet displaying GAD-immunoreactive terminals on its soma. stained too faintly, or perhaps the cytoplasm of small cells may be difficult to detect in thick sections.

If neurons having local circuit connections could be marked in some way, then the question of whether they also have axons that project to cortex might be answered by combining the marker with retrograde HRP transport from cortex. In particular, if local circuit neurons are characterized by GAD immunoreactivity, then the brown immunocytochemical stain should make them easy to detect and evaluate for HRP labeling. This is what we believe we have done, although this interpretation is by no means certain and depends on the consideration of two prior questions. First, was the failure to observe neurons labeled for both GAD immunoreactivity and HRP transport specious? Second, do the GAD-immunoreactive neurons have other characteristics that make them likely candidates for local circuit neurons?

With respect to the first question we can imagine two sources of misleading results from the experiments combining HRP transport and GAD immunocytochemistry. A first possibility is that GAD-immunoreactive neurons project to the cerebral cortex and transport HRP to their cell bodies, but that the two reaction methods used for the HRP and GAD procedures are incompatible, preventing both labels from being visualized in the same cell body. We rule out this incompatibility by showing that GAD-immunoreactive cells can be double labeled by the local uptake of HRP.

A second possible source for a misleading result could be the failure of a projecting axon from GAD-immunoreactive neurons to take up or transport HRP in quantities sufficient to be detected. This cannot be ruled out, but at least we know that not all GAD-immunoreactive
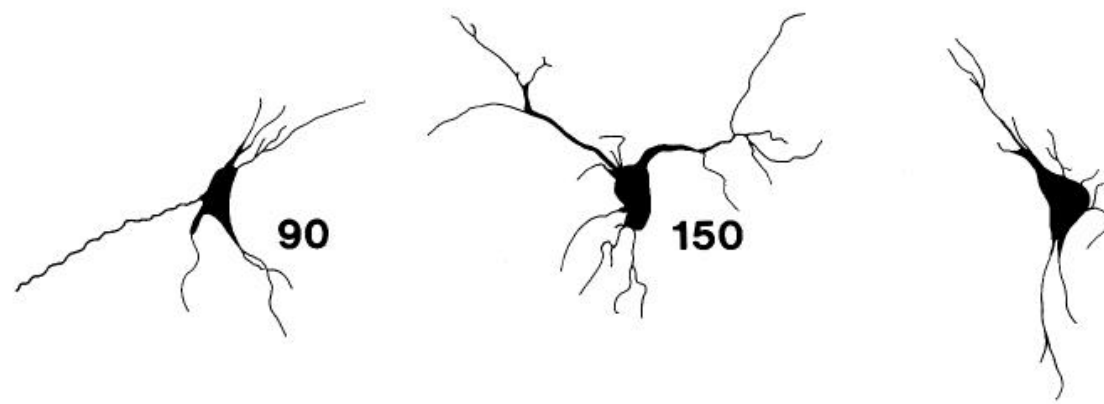

160

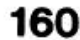

\section{$50 \mu \mathrm{m}$}
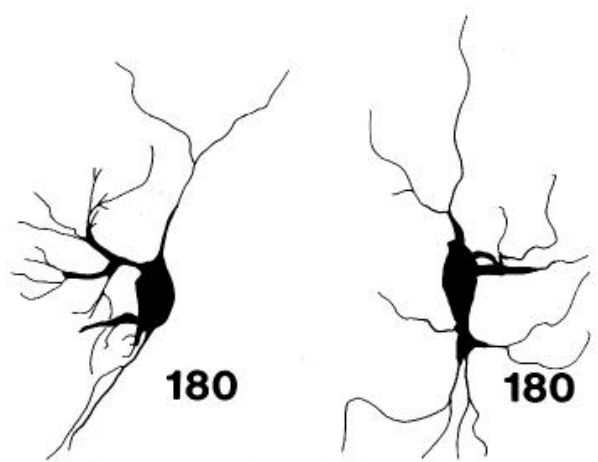

Figure 18. Drawings of typical small projection cells in the ventral posterior nucleus of the cat. These cells were filled by HRP transported from cortex. The cell soma area in square micrometers of each neuron is indicated. 

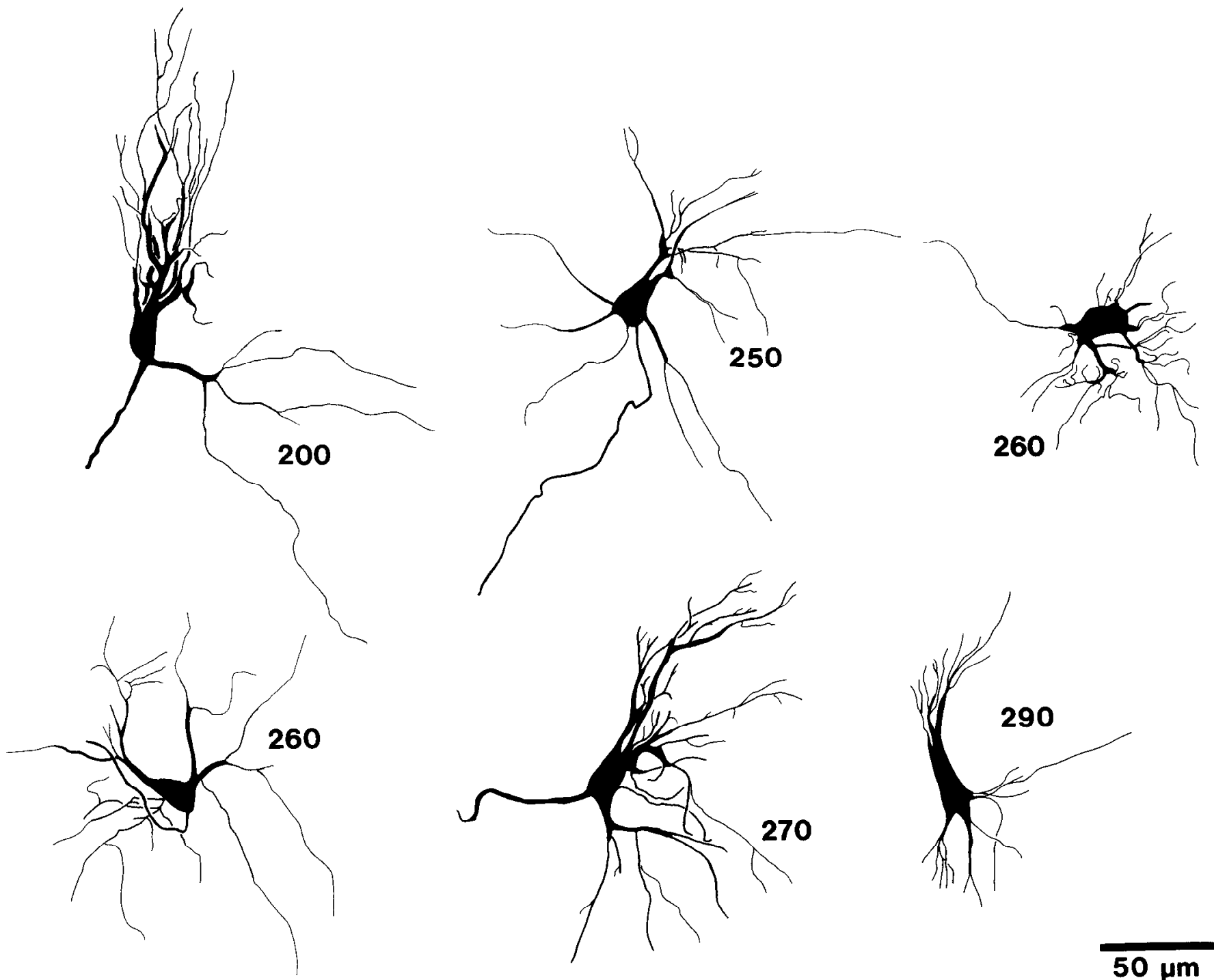

Figure 19. Drawings of typical projection neurons of medium size in the ventral posterior nucleus of the cat. These cells were filled by HRP transported from cortex. The cell soma area in square micrometers of each neuron is indicated.

neurons fail to take up and transport HRP; in a subsequent paper on the lateral geniculate nucleus we will describe GAD-immunoreactive neurons in the perigeniculate nucleus that are labeled by the retrograde transport of HRP.

Suppose that the GAD-immunoreactive cells do not project to somatosensory area I, which we feel to be a reasonable interpretation of our results. This would not permit us to argue that the cells do not project to other areas of the cortex or other centers. However, the possibility that GAD-immunoreactive cells project to other subdivisions of the somatic cortex is unlikely on the evidence from the studies of anterograde and retrograde transport (Jones and Powell, 1969; Jones, 1975a; Friedman and Jones, 1980; Koser and Hand, 1981; Spreafico et al., 1981; Penny et al., 1982a). The possibility of a projection from the GAD-positive cells of the ventral posterior nucleus to the reticular nucleus remains viable (Schiebel and Schiebel, 1966; Jones, 1975b).

If the GAD-immunoreactive neurons are local circuit neurons and do not project to somatosensory cortex, then we must account for the results of Saporta and Kruger (1979) in which almost all neurons were labeled after cortical injections of HRP, leading them to question the existence of thalamic local circuit neurons. This was a reasonable doubt based on the data, and the differences between their results and ours can be explained by the differences in methods. First, the scanty cytoplasm of small neurons is sometimes difficult to identify with the Nissl stain in thick frozen sections; thinner sections may provide a better opportunity for seeing very small and pale cells. Second, the GAD-immunoreactive neurons within the ventral posterior nucleus are aggregated in small clusters, leaving other nearby patches free of these neurons, as shown in Figure 9. Such a distribution might lead to the possibility that any given small sample is free of GAD cells. By this argument, samples of labeled and unlabeled neurons over large areas should support the present findings, and they do. By taking large samples of neurons from thin plastic embedded sections, Spreaf- 

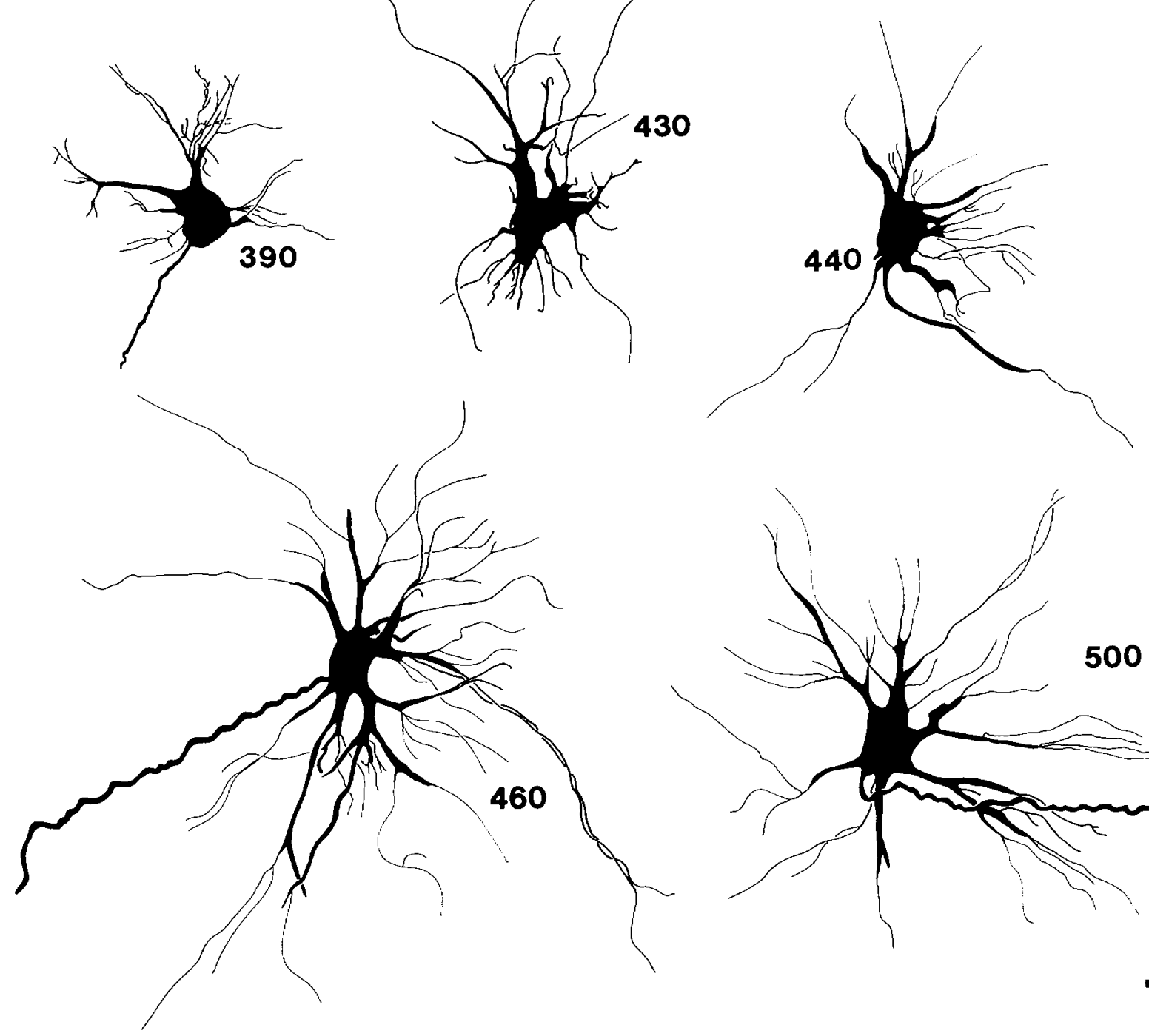

Figure 20. Drawings of typical projection neurons of large size in the ventral posterior nucleus of the cat. These cells were filled by HRP transported from cortex. The cell soma area in square micrometers of each neuron is indicated.

ico et al. (1983) have been able to show that about $20 \%$ of the neurons in the cat ventral posterior nucleus are left unlabeled after cortical HRP injections. Pearson and Haines (1980b) have obtained similar results in Galago.

The second question is: "Do the GAD-immunoreactive neurons have characteristics other than failing to project to cortex that make them likely candidates for local circuit neurons?" We find first that the GAD immunoreactive neurons have morphological features similar to the traditional description of the local circuit neurons provided by Ramón y Cajal $(1909,1966)$. Ramón y Cajal described short axon cells as having ovoid, fusiform, or triangular cell bodies and three or four primary dendrites with little tendency to branch (see also the 1983 paper by Spreafico et al. in which one of the present authors (D. E. S.) participated). Second, we were able to describe a number of morphological classes of HRP-filled projection neurons based on cell body size and dendritic morphology, and all of these classes differ from the GADimmunoreactive neurons. Note that some small HRP cells do not differ from the GAD-immunoreactive neurons on the hasis of size but are clearly different in dendritic morphology. Third, the morphology of the HRP-filled neurons differs from the traditional description of local circuit neurons provided by Cajal.

In summary, we have argued that the best interpretation of the present results is that GAD immunoreactivity is a marker for local circuit neurons in the ventral posterior nucleus. This conclusion, we concede, is short of being proven beyond doubt. However, if the conclusion proves to be right, it is not insignificant because hitherto there has been no unambiguous way to identify a local circuit neuron. Because GABA is regarded as an inhibitory neurotransmitter, our argument has implications for the role of local circuit neurons in the thalamus, and we shall come back to this point.

$G A D$-immunoreactive terminals and processes. In addition to the GAD-immunoreactive neurons in the ventral posterior nucleus, we also found many GAD-immunoreactive terminals filling the nucleus. This finding raises the question: "What is the source of such terminals?" One source must be the GAD-immunoreactive cells themselves, distributed within the ventral posterior nucleus. Indeed, we can trace processes from GAD-posi- 
tive cells which terminate in drumstick-like enlargements, and in the cat these structures are gathered into prominent clusters. Although an electron microscopic analysis is necessary to determine whether these are presynaptic dendritic specializations, it is reasonable to suggest that they might correspond to the endings described by Ralston and his collaborators $(1968,1971 \mathrm{a}$, 1971b) and Famiglietti and Peters (1972).

There is a second potential source of the GAD-immunoreactive terminals in the ventral posterior nucleus since the reticular nucleus of the ventral thalamus is filled with GAD-immunoreactive cells that project to the dorsal thalamus (Schiebel and Schiebel, 1966; Jones, 1975b; Houser et al., 1980). Furthermore, the cells of the reticular nucleus have an inhibitory influence on the thalamocortical relay cells in the ventral group of nuclei (Mukhametov et al., 1970; Filion et al., 1971; Lamarre et al., 1971; Schlag and Waszak, 1971; Frygyesi and Schwartz, 1972; Steriade and Wyzinski, 1972).

The organization of the terminals found in the ventral posterior nucleus provides a noteworthy species difference. In the cat the terminals associated with the processes of GAD-immunoreactive neurons in the ventral posterior nucleus are gathered into large clusters. Similar terminals are present in the Galago, but in this species clusters are rarely observed. Furthermore, in the cat, although GAD-immunoreactive neurons and terminals are found in most thalamic nuclei, clusters are not. Instead, these terminal clusters are confined to the lateral geniculate body, the medial geniculate body, the ventral posterior nucleus, the pulvinar and the rostrallateralmost subdivision of the central lateral nucleus. It is not unreasonable to suggest that these clusters represent a special common function to these nuclei.

$G A D$-immunoreactive neurons in the ventral posterior nucleus of the cat and Galago: implications for thalamic organization. About $30 \%$ of the neurons in the ventral posterior nucleus are GAD immunoreactive and, therefore, probably GABAergic. Although we cannot prove that the GABAergic neurons fail to project outside the thalamus, it is almost a certainty that they are involved in local circuits and thus inhibit the cells that project to the cortex. Inhibitory systems within the ventral posterior nucleus have been identified by physiological methods (Anderson and Eccles, 1962; Anderson et al., 1964a, b), but the complex role of inhibition at the cellular level is beyond the scope of the present discussion. The chief contribution of the present paper is to show by immunocytochemistry the substantial proportion of inhibitory cells in two distantly related species and to show by HRP transport methods that these neurons may lack connections with the cerebral cortex. This result supports the idea that the dorsal thalamus, and the ventral posterior nucleus in particular, is not a passive relay station in the pathway to the cortex. Instead, the thalamus must be involved in what might be called sensory processing, that is, the sort of neural integration which takes place in the retina and other sensory centers in which other local circuit neurons are a crucial link between incoming and outgoing impulses. We have reason to believe that the small local circuit neurons are the targets of ascending afferent fibers, but we need to know more about the other connections before we can speculate about the behavioral significance of inhibition in the thalamus. For example, it would be useful to know whether local circuit neurons are the special targets of descending projections from cortical layer VI neurons (Jones and Wise, 1977; Wise and Jones, 1977) and whether they receive fibers from brain stem centers that are not identified with one single sensory system and, thus, may convey signals about the general state of the organism. Finally, since the ventral posterior nucleus represents the body surface as well as different receptors or "submodalities" (Dykes, 1982), it is natural to wonder whether inhibitory local circuit cells play any role in adjusting the threshold for somatotopic discrimination or in relating information conveyed by the various submodalities.

\section{References}

Adams, J. C. (1977) Technical considerations on the use of horseradish peroxidase as a neuronal marker. Neuroscience 2: $141-145$.

Anderson, P., and J. C. Eccles (1962) Inhibitory phasing of neuronal discharge. Nature 196: 645.

Anderson, P., C. McC. Brooks, J. C. Eccles, and T. A. Sears (1964a) The ventrobasal nucleus of the thalamus: Potential fields, synaptic transmission and post-synaptic components. J. Physiol. (Lond.) 174: 348-369.

Anderson, P., J. C. Eccles, and T. A. Sears (1964b) The ventrobasal complex of the thalamus: Types of cells, their responses and their functional organization. J. Physiol. (Lond.) 174: $370-399$.

Berkley, K. J. (1980) Spatial relationships between the terminations of somatic sensory and motor pathways in the rostral brainstem of cats and monkeys. I. Ascending somatic sensory inputs to the lateral diencephalon. J. Comp. Neurol. 193: 283-317.

Boive, J. (1971) The termination of the spinothalamic tract in the cat. An experimental study with silver degeneration methods. Exp. Brain Res. 12: 331-353.

Brooks, C. McC., and J. C. Eccles (1947) An electrical hypothesis of central inhibition. Nature 159: 760-764.

Dykes, R. W. (1982) Parallel processing of cutaneous information in the somatosensory system of the cat. Can. J. Neurol. Sci. 9: 9-19.

Eccles, J. C., P. Fatt, and K. Kotetsu (1954) Cholinergic and inhibitory synapses in a pathway from motor-axon collaterals to motor neurons. J. Physiol. (Lond.) 126: 524-562.

Eccles, J. C., P. Fatt, and S. Landgren (1956) Central pathway for direct inhibitory action of impulses in largest afferent nerve fibers to muscle. J. Neurophysiol. 19: 75-98.

Fahn, S. (1976) Regional distribution studies of GABA and other putative neurotransmitters and their enzymes. In GABA in Nervous System Function, E. Roberts, T. N. Chase, and D. B. Tower, eds., pp. 169-186, Raven Press, New York.

Famiglietti, E. V., and A. Peters (1972) The synaptic glomerulus and the intrinsic neuron in the dorsal lateral geniculate of the cat. J. Comp. Neurol. 144: 285-334.

Filion, M., Y. Lamarre, and J. P. Cordeau (1971) Neuronal discharges of the ventrolateral nucleus of the thalamus during sleep and wakefulness in the cat. II. Evoked activity. Exp. Brain Res. 12: 499-508.

Fitzpatrick, D., G. R. Penny, D. E. Schmechel, and I. T. Diamond (1982) GAD immunoreactive neurons in the lateral geniculate nucleus of the cat and Galago. Soc. Neurosci. Abstr. 8: 261.

Fonnum, F., and F. Wallberg (1973) An estimation of concentration of $\gamma$-aminobutyric acid and glutamate decarboxylase 
in the inhibitory Purkinje axon terminals in the cat. Brain Res. 54: 115-127.

Fox, C. A., A. A. Andrade, D. E. Hillman, and R. C. Schwin (1971) The spiny neurons and the glia in the primate striatum: a Golgi and electron microscope study. J. Hirnforsch. 13: 181-201.

Friedman, D. P., and E. G. Jones (1980) Focal projections of electrophysiologically defined groupings of thalamic cells on the monkey somatic cortex. Brain Res. 191: 249-252.

Frygyesi, T. L., and R. Schwartz (1972) Cortical control of thalamic sensory-motor relay activities in the cat and the squirrel monkey. In Corticothalamic Projections and Sensorimotor Activities, T. L. Frygesi, E. Rinvik, and M. D. Yahr, eds., pp. 161-195, Raven Press, New York.

Guillery, R. W. (1966) A study of Golgi preparations from the dorsal lateral geniculate nucleus of the adult cat. J. Comp. Neurol. 128: 21-50.

Houser, C. R., J. E. Vaughn, R. P. Barber, and E. Roberts (1980) GABA neurons are the major cell type of the nucleus reticularis thalami. Brain Res. 200: 341-354.

Hsu, S. M., L. Raine, and H. Ganger (1981) 'The use of avidinbiotin-peroxidase complex $(\mathrm{ABC})$ in immunoperoxidase techniques: A comparison between $\mathrm{ABC}$ and unlabeled antibody (PAP) procedures. J. Histochem. Cytochem. 29: $577-$ 580 .

Jones, E. G. (1975a) Lamination and differential distribution of thalamic afferents within the sensory-motor cortex of the squirrel monkey. J. Comp. Neurol. 160: 167-204.

Jones, E. G. (1975b) Some aspects of the organization of the thalamic reticular complex. J. Comp. Neurol. 162: 285-308.

Jones, E. G., and H. Burton (1974) Cytoarchitecture and somatic sensory connectivity of thalamic nuclei other than the ventrobasal complex in the cat. J. Comp. Neurol. 154: 395432.

Jones, E. G., and D. P. Friedman (1981) A thalamic basis for the place and modality specific columns of monkey somatic sensory cortex. Soc. Neurosci. Abstr. 7: 832.

Jones, E. G., and T. P. S. Powell (1969) The cortical projection of the ventroposterior nucleus in the cat. Brain Res. 13: 298318.

Jones, E. G., and S. P. Wise (1977) Size, laminar and columnar distribution of efferent cells in the sensory motor cortex of monkeys. J. Comp. Neurol. 175: 391-438.

Kemp, J. M., and T. P. S. Powell (1971) The structure of the caudate nucleus of the cat: Light and electron microscopy. Philos. Trans. R. Scc. Lond. Biol. 262: 383-401.

Kosor, E., and P. J. Hand (1981) First somatosensory cortical columns and associated neuronal clusters of nucleus ventralis posterolateralis of the cat: An anatomical demonstration. J. Comp. Neurol. 198: 515-539.

Kuriyama, K., L. B. Haber, B. Sisken, and E. Roberts (1966) The $\gamma$-aminobutyric acid system in rabbit cerebellum. Proc. Natl. Acad. Sci. U. S. A. 55: 846-852.

Lamarre, Y., M. Filion, and J. P. Cordeau (1971) Neuronal discharges of the ventrolateral nucleus of the thalamus during sleep and wakefulness in the cat. I. Spontaneous activity. Exp. Brain Res. 12: 480-498.

McLaughlin, B. J., J. G. Wood, K. Saito, R. Barber, J. E. Vaughn, E. Roberts, and J. -Y. Wu (1974) 'I 'he fine structural localization of glutamate decarboxylase in synaptic terminals of rodent cerebellum. Brain Res. 76: 377-391.

Mugnaini, E., and A. L. Dahl (1983) Zinc-aldehyde fixation for light microscopic immuncytochemistry of nervous tissues. J. Histochem. Cytochem., in press.

Mukhametov, V. M., G. Rizzolatti, and V. Tradardi (1970) Spontaneous activity of neurons of nucleus reticularis thalami in freely moving cats. J. Physiol. (Lond.) 210: 651-667.

Nakane, P. K. (1968) Simultaneous localization of multiple tissue antigens using the peroxidase-labeled antibody method: A study on pituitary glands of the rat. J. Histochem. Cytochem. 16: 557-560.

Oertel, W. H., D. E. Schmechel, M. L. Tappaz, and I. J. Kopin (1981) Production of a specific antiserum to rat brain glutamic acid decarboxylase by injection of an antigen-antibody complex. Neuroscience 6: 2689-2700.

Oertel, W. H., E. Mugnaini, and D. E. Schmechel (1983) Glutamate decarboxylase (GAD) purification, antiserum production, immunocytochemistry. In Current Methods in Cellular Neurobiology, J. L. Barker and J. F. McKelly, eds., John Wiley \& Sons, New York, in press.

Pearson, J. C., and D. E. Haines (1980a) Somatosensory thalamus of a prosimian primate (Galago senegalensis). I. Configuration of nuclei and termination of spinothalamic fibers. $\mathrm{J}$. Comp. Neurol. 190: 533-558.

Pearson, J. C., and D. E. Haines (1980b) Somatosensory thalamus of a prosimian primate (Galago senegalensis). II. An HRP and Golgi study of the ventral posterolateral nucleus (VPL). J. Comp. Neurol. 190: 559-580.

Penny, G. R., K. Itoh, and I. T. Diamond (1982a) Neurons of different sizes in the ventral nuclei project to different layers of the somatic cortex in cats. Brain Res. 212: 55-65.

Penny, G. R., D. Fitzpatrick, D. Schmechel, and I. T. Diamond (1982b) GAD immunoreactive neurons in the ventral posterior nucleus of cat and Galago. Soc. Neurosci. Abstr. 8: 38.

Poggio, G. F., and V. B. Mountcastle (1960) A study of the functional contributions of the lemniscal and spinothalamic systems to somatic sensitivity. Central nervous mechanisms in pain. Johns Hopkins Hosp. Bull. 106: 226-316.

Preston, R. J., G. A. Bishop, and S. T. Kitai (1980) Medium spiny neuron projection from the rat striatum: An intracellular horseradish peroxidase study. Brain Res. 183: 253-262.

Rakic, P. (1976) Local Circuit Neurons, MIT Press, Cambridge, MA.

Ralston, H. J. (1971a) Evidence for presynaptic dendrites and a proposal for their mechanism of action. Nature 230: 585587.

Ralston, H. J. (1971b) The synaptic organization in the dorsal horn of the spinal cord and in the ventrobasal thalamus in the cat. In Oral-Facial Sensory and Motor Mechanisms, R. Dabner and Y. Kawamura, eds., pp. 229-250, AppletonCentury-Crofts, New York.

Ralston, H. J., and M. M. Herman (1968) The fine structure of neurons and synapses in the ventrobasal thalamus of the cat. Brain Res. 14: 77-97.

Ramón y Cajal, S. (1909) Histologie du Systeme Nerveux de l'Homme et des Vertebres, Paris.

Ramón y Cajal, S. (1966) Studies on the Diencephalon, E. Ramon-Moliner, transl. Charles C Thomas, Springfield, IL.

Roberts, E., and K. Kuriyama (1968) Biochemical-physiological correlations in studies of the $\gamma$-aminobutyric acid system. Brain Res. 8: 1-35.

Rose, J. E., and C. N. Woolsey (1958) Cortical connections and functional organization of the thalamic auditory system of the cat. In Biological and Biochemical Bases of Behavior, $\mathrm{H}$. F. Harlow and C. N. Woolsey, eds., pp. 127-150, University of Wisconsin Press, Madison.

Saporta, S., and L. Kruger (1979) The organization of projections to selected points of somatosensory cortex from cat ventrobasal complex. Brain Res. 178: 275-295.

Schiebel, M. E., and A. B. Schiebel (1966) The organization of the nucleus reticularis thalami: A Golgi study. Brain Res. 1: $43-62$.

Schlag, J., and M. Waszak (1971) Electrophysiological properties of units in the thalamic reticular complex. Exp. Neurol. 32: 79-97.

Siegel, S. (1956) Nonparametric Statistics for the Behavioral 
Sciences, McGraw-Hill, New York.

Spreafico, R., N. L. Hayes, and A. Rustioni (1981) Thalamic projections to the primary and secondary somatosensory cortices in cat: Single and double retrograde tracer studies. J. Comp. Neurol. 203: 67-90.

Spreafico, R., D. E. Schmechel, L. C. Ellis, and A. Rustioni (1983) Cortical relay neurons and interneurons in the $\mathrm{N}$. ventralis posterolateralis of cats: An HRP, EM, Golgi and immunocytochemical study. Neuroscience, in press.

Steriade, M., and P. Wyzinski (1972) Cortically-elicited activities in the thalamic reticularis neurons. Brain Res. 42: 514-
520.

Sternberger, L. A. (1979) Immunocytochemistry, Ed. 2, John Wiley \& Sons, New York.

Streit, P., and J. C. Ruebi (1977) A new and sensitive staining method for axonally transported horseradish peroxidase (HRP) in the pigeon visual system. Brain Res. 126: 530-537.

Tömböl, T. (1967) Short neurons and their synaptic relations in the specific thalamic nuclei. Brain Res. 3: 307-326.

Wise, S. P., and E. G. Jones (1977) Cells of origin and terminal distribution of descending projections of the rat somatic sensory cortex. J. Comp. Neurol. 175: 129-158. 